Review Article

\title{
A Review of Smart Contracts Applications in Various Industries: A Procurement Perspective
}

\author{
Yongshun Xu $\mathbb{D},{ }^{1}$ Heap-Yih Chong $\mathbb{D}^{2},{ }^{2}$ and Ming Chi $\mathbb{D}^{1}$ \\ ${ }^{1}$ School of Management, Jilin University, Changchun 130022, China \\ ${ }^{2}$ School of Design and the Built Environment, Curtin University, GPO Box U1987, Perth, WA 6845, Australia \\ Correspondence should be addressed to Heap-Yih Chong; heap-yih.chong@curtin.edu.au
}

Received 10 January 2021; Revised 13 February 2021; Accepted 10 April 2021; Published 21 April 2021

Academic Editor: Wen Yi

Copyright ( 92021 Yongshun Xu et al. This is an open access article distributed under the Creative Commons Attribution License, which permits unrestricted use, distribution, and reproduction in any medium, provided the original work is properly cited.

Smart contracts have been well-received by researchers and practitioners for the unique features of automatic execution, transparency, and nontampering in a blockchain environment. However, little is known about the current development status of knowledge and practice regarding the application of smart contracts in various industries, especially from the procurement perspective. Thus, this paper aims to address the gap with a mixed method of bibliometric analysis and systematic literature review. Based on the evaluation of 174 filtered publications, the review has analyzed the current development status of this research area with its distributions in years and journals, cooperation networks between authors, institutions, and countries, keywords cooccurrence network, and classifications of the application of smart contracts. The results show the application of smart contracts has attracted global attention since 2016 with the Ethereum and Hyperledger fabric as the main platforms in various industries, especially in information communication technology (ICT), public management, supply chain, energy, finance, and healthcare. Various functions and benefits of smart contracts, as well as their potential advantages, have been identified and articulated from the procurement perspective. A research framework has also been developed to highlight future procurement needs in business operations across the industries via an integrated procurement approach of smart contracts.

\section{Introduction}

With the advent of blockchain technology, smart contracts have become one of the most sought-after technologies [1]. Smart contract is a new technology that can automatically negotiate, fulfil, and enforce the terms of an agreement in a blockchain environment [2]. Compared with traditional contracts, smart contracts have the advantages of diminishing risk, cutting down administration and service costs, and improving the efficiency of business processes [3]. More importantly, smart contracts have the capacity to create trust between parties in what we term no-trust contracting environments [4]. In this regard, it will reshape business processes and even transform conventional practices [5].

Due to these benefits, smart contracts have recently fueled extensive research interests [2]. Smart contracts have the potential to be used in various industries. For example,
Hasan et al. [6] proposed a method based on smart contracts for effective shipment management. Wang et al. [7] pointed out that smart contracts can be applied to the financial loan management system. Khatoon [8] revealed the practical benefits of smart contracts in healthcare management. Moreover, researchers also attempted to evaluate the application of the smart contract. For example, Macrinici et al. [1] identified 16 smart contract problems and offered corresponding solutions through a literature review. Wang et al. [9] presented several typical application scenarios of the smart contract and discussed the future development trends. Rouhani and Deters [2] reviewed the security, performance, and application of smart contracts. Zheng et al. [5] compared several major smart contract platforms and categorized smart contract applications.

The current procurement system faces greater challenges in transaction security, information exchange, business process, payment delay, and traceability [10]. Smart 
contracts have the characteristics to solve these issues digitally. The potential of smart contracts is of significance to the improvement and transformation of the traditional procurement pattern $[11,12]$. While prior studies have shed some lights on the application of smart contracts, there is still a lack of holistic understanding across industries, especially from the procurement perspective. To address this gap, the purpose of this study is to systematically review the application of smart contracts in various industries, which is mainly to answer the following questions:

RQ1. What is the current development status of smart contract applications?

RQ2. What are the benefits of smart contracts applications in various industries from the procurement perspective?

RQ3. What are the potential advantages of smart contracts in the procurement process?

The mixed-method approach of bibliometric analysis and systematic review was adopted to analyze the research works on smart contracts' applications. Subsequently, a research framework of smart contracts was developed for future procurement needs from both theoretical and practical perspectives. The remainder of this paper is organized as follows. Section 2 provides a brief background overview of blockchain, smart contract, and procurement; Section 3 describes the research methodology; Sections 4 and 5 present the results; Section 6 presents the discussion and future procurement requirements0020framework; Section 7 summarizes the research conclusions and research limitations.

\section{Background}

2.1. Blockchain. Blockchain technology originated from the foundational paper "Bitcoin: A peer-to-peer electronic cash system" published by Satoshi Nakamoto in 2008 [13]. This technology is essentially a decentralized database as per its underlying bitcoin technology, which provides new technical solutions without relying on a third party to carry out the storage, verification, transmission, and communication of network data through its own distributed nodes. It is also considered the most disruptive technology innovation after the invention of the Internet [14]. The reason is that, based on its clever mathematical cryptography and distributed algorithm, participants can reach consensus and transmit trust and value reliably at a meagre cost without the thirdparty intermediate [4].

The development of blockchain technology can be generally categorized into three stages, that is, the application of digital currency in the initial 1.0 stage, the application of smart contract in the 2.0 stage, and the programmable blockchain 3.0 stage $[15,16]$. It is currently in the second stage of development, where blockchain is still mainly used in small-scale local applications, with few real industry-level or eco-level applications. Even so, the unique features of blockchain technology have started spreading over many industries [17].
2.2. Smart Contract. The concept of smart contracts was first proposed in the 1990s by Nick [18]. However, smart contracts were buried and failed to attract the attention of the industry and academia for quite some time as there was no platform to execute smart contracts before the emergence of blockchain technology in 2009 [3]. By contrast, the heyday of smart contracts has already begun. Especially since the establishment of Ethereum based on blockchain technology, the development of smart contracts has become popular. Up to date, except Ethereum, there are numerous alternative blockchain-based platforms for executing smart contracts including Hyperledger fabric, Corda, Stellar, Rootstock, EOS, etc. [5]. In this way, the blockchain and smart contracts have been growing and functioning mutually.

Unlike contracts in the real world, smart contracts are entirely digital and essentially containers of code that encode [1]. Smart contracts refer to a computer protocol, which can be self-executed and self-verified once developed and deployed without any human interventions [14]. Smart contracts can create trust among parties in a no-trust contracting environment [4]. The terms and conditions embedded in smart contracts will be enforced automatically when certain criteria have been satisfied. Compared with traditional contracts, smart contracts have the advantages of decreasing transaction risk, diminishing management and service costs, and improving business process efficiency as they are typically deployed on and protected by blockchain [5]. In this connection, smart contracts are expected to provide a better solution to the current transaction mode in various industries.

2.3. Procurement. Procurement is the act of acquiring goods or services from an external source [19]. Ordinary purchases are simple acts in procurement, while a complex procurement includes more complicated processes such as requirement determination, source selection, quotation request, vendors selection, etc. In general, the traditional procurement system requires employees to coordinate vast amounts of paperwork [20]. Apart from that, there are many intermediaries, long processing times, potential collusions, information delay, and trust issues in the traditional procurement system, which hinder the efficiency of the overall procurement performance [21]. Nowadays, based on the digital technology, procurement has begun to change from traditional procurement system to an electronic procurement approach, which can be described as a comprehensive ICT process to establish agreements for the acquisition of products or services (contracting) or purchase products or services in exchange for payment (purchasing). This electronic procurement approach will alter the way businesses or individuals purchase. It could overcome certain shortcomings of the traditional procurement system, such as low transaction security, lack of trust, repetitive verification, and payment delays.

The development of blockchain and smart contracts provides new possibilities for procurement. Blockchain, especially smart contracts, is subverting the traditional procurement model. Kamali [22] pointed out that the 
application of blockchain and smart contracts can prevent corruption and fraud in the procurement process. Chong and Diamantopoulos [23] indicated that smart contracts effectively address the security of payment problems in the construction industry. Hasan et al. [6] demonstrated that smart contracts could be used to manage shipment conditions, automate payments, legitimize receiver, and issue a refund in case of violating the predefined terms. Jangir et al. [24] revealed that smart contracts could help achieve user privacy protection, data transparency, immutability nonrepudiation, real-time tracking of commodities, and demand-supply management. Elghaish et al. [11] underlined the possible future extension for smart contracts, which would be revolutionizing the structure of traditional procurement systems, such as the design-build (DB) method. From the procurement perspective, smart contracts constitute business logic that is related to purchasing transactions [10]. In summary, smart contracts have a great potential to extend existing procurement tools or practices by automatizing their transactional processes.

\section{Methodology}

A combination of bibliometric analysis and systematic review was adopted to locate and analyze existing research related to the application of smart contracts in various industries. The systematic review is defined as a literature review method that identifies, evaluates, and analyzes published primary studies to answer specific research questions [25]. It mainly relies on personal and intentional selected materials deemed important, enabling researchers to go beyond their own experience and conduct a comprehensive search of all existing publications of interest. More importantly, the systematic evaluation reduces the bias of researchers because it uses a predefined sequential search strategy, thereby increasing the transparency of the method and thus allowing future replication [26]. The specific review process and strategy are as follows.

\subsection{Information Sources and Search Strategy. Scopus and} Web of Science were selected as the main sources of retrieval due to their more comprehensive coverage of scientific publications and quicker indexing processes. That would help in increasing the possibility of retrieving more relevant publications. The data collection was conducted initially in January 2020, and it was updated and supplemented with more papers for the final analysis in June 2020. The generic term "smart contract" was used for the retrieval to cover as many publications as possible for this review. The formulated search string was as follows: (TITLE ("smart contract") OR ABS ("smart contract") OR KEY ("smart contract")).

3.2. Publication Selection and Evaluation. The subsequent screening procedure was carried out to filter the relevant publications based on the following three steps. First, articles were screened through the topic refinement within the databases to eliminate any duplicate articles. Second, the filtered papers were further analyzed for their titles and abstracts from the procurement perspective. Finally, the related publications were downloaded in full and reviewed systematically after checking against inclusion and exclusion criteria, as shown in Table 1. Considering that the topic is still relatively new, the literature search was conducted without any time restrictions until June 2020. We focused only on the literature in academic journals and conference papers to ensure the quality and coverage of the scientific knowledge of smart contracts in various industries. Meanwhile, we excluded articles focused on the technical aspects or algorithms' developments in blockchain and smart contracts. The whole screening process was completed by three members, two of whom were screened in a backto-back manner. Then, the results were compared, and three members discussed the results with differences until a consensus was reached. Finally, 174 publications were selected for this review paper, as shown in Table 2. Figure 1 illustrates the overall flow of the review process and strategy.

Based on the above, we also synthesized the data by looking at the year of publication, type of publication, blockchain platform, and application domain. Apart from these, the application level of smart contract was classified according to Udokwu et al. [194] and Batubara et al. [195]. The results were presented in appendix A. The level of application was segmented as theoretical description, proposed framework/method, system architecture, prototype, and implementation. Besides, a preliminary descriptive statistical analysis was further conducted to understand the selected publications better. We used VOS viewer software to analyze the keyword cooccurrence network, cooperation networks between authors, institutions, countries, and author cocitation network. In this way, more intuitive answers could be uncovered for the research questions.

\section{Results of the Bibliometric Analysis}

In this section, we attempt to find an answer to RQ1. What is the current development status of smart contract applications?

4.1. Chronological Publication Trend. Figure 2 shows the publication trend of related research on smart contract applications. Although we did not set a time limit, the first related paper emerged in 2016. That indeed indicates that the research of smart contracts is relatively new. Apart from that, it can be found from the trend line that both journal papers and conference papers have been developing rapidly in recent three years. Among them, 83 publications were published in 2019, and 38 publications were published in the first half of 2020. It is worth noting that the number of conference papers had increased faster than journal papers in the initial stage. That was mainly due to the reporting of the preliminary research outcomes or proof-of-concept studies at the early stage of research development. Still, the number of journal papers had grown significantly faster since 2019, indicating that the research has become more established and popular in academia. 
TABLE 1: Inclusion and exclusion criteria.

Selection criteria
$\begin{gathered}\text { Sithout time-frame restrictions } \\ \text { Anclusion }\end{gathered}$
Article or conference paper
Related to the application, use, and adoption of smart contracts
Non-English articles, articles with missing abstract, full text not available
A generic literature review

TABLE 2: Research papers included in the systematic review and their characteristics.

\begin{tabular}{|c|c|c|c|c|c|}
\hline No. & Author (year) & Source type & Application domains & Blockchain platform & Level of application \\
\hline 1 & Bogner et al. (2016) [27] & Conference & Sharing economy & Ethereum & System architecture \\
\hline 2 & $\begin{array}{l}\text { Christidis and Devetsikiotis. (2016) } \\
\text { [28] }\end{array}$ & Journal & IoT & $\mathrm{N} / \mathrm{A}$ & $\begin{array}{l}\text { Theoretical } \\
\text { description }\end{array}$ \\
\hline 3 & Nugent et al. (2016) [29] & Journal & Healthcare & Ethereum & Prototype \\
\hline 4 & Yasin and Liu (2016) [30] & Conference & Online identity & N/A & System architecture \\
\hline 5 & McCorry et al. (2017) [31] & Conference & Voting & Ethereum & Implementation \\
\hline 6 & Thomas et al. (2017) [32] & Conference & Energy & Ethereum & Prototype \\
\hline 7 & Hans et al. (2017) [33] & Conference & Finance & Ethereum & $\begin{array}{l}\text { Theoretical } \\
\text { description }\end{array}$ \\
\hline 8 & Kounelis et al. (2017) [34] & Conference & Energy & Ethereum & Prototype \\
\hline 9 & Gazali et al. (2017) [35] & Conference & Education & Ethereum & Prototype \\
\hline 10 & Hahn et al. (2017) [36] & Conference & Energy & Ethereum & Prototype \\
\hline 11 & Álvarez-Díaz et al. (2017) [37] & Conference & Logistics management & Ethereum & Proposed method \\
\hline 12 & Saravanan et al. (2017) [38] & Conference & ICT & Ethereum & Proposed method \\
\hline 13 & Sreehari et al. (2017) [39] & Conference & Public management & Ethereum & Proposed method \\
\hline 14 & Shermin (2017) [40] & Journal & Governance & Bitcoin, Ethereum & $\begin{array}{l}\text { Theoretical } \\
\text { description }\end{array}$ \\
\hline 15 & Mason (2017) [41] & Journal & Construction & N/A & $\begin{array}{l}\text { Theoretical } \\
\text { description }\end{array}$ \\
\hline 16 & Kirkman (2018) [42] & Conference & Cloud & Ethereum & Proposed framework \\
\hline 17 & Wang et al. (2018) [43] & Conference & Prediction market & Ethereum & Implementation \\
\hline 18 & Hou et al. (2017) [44] & Conference & Electric vehicles & NA & Proposed method \\
\hline 19 & Yeh et al. (2018) [45] & Journal & Mobile payment & Ethereum & Proposed method \\
\hline 20 & Desai et al. (2018) [46] & Conference & Data sharing & Ethereum & Proposed framework \\
\hline 21 & Mahmoud et al. (2018) [47] & Conference & Finance & Ethereum & Prototype \\
\hline 22 & Rozario and Vasarhelyi. (2018) [48] & Journal & Finance & NA & $\begin{array}{l}\text { Theoretical } \\
\text { description }\end{array}$ \\
\hline 23 & Chen et al. (2018) [49] & Conference & E-commerce & Ethereum & System architecture \\
\hline 24 & Zhao and O'Mahony (2018) [50] & Conference & Entertainment & Ethereum & Prototype \\
\hline 25 & Zhong et al. (2018) [51] & Conference & Electric vehicle & Ethereum & Proposed method \\
\hline 26 & Gupta and Bedi (2018) [52] & Conference & Public management & Ethereum & Prototype \\
\hline 27 & Griggs et al. (2018) [53] & Journal & Healthcare & Ethereum & Prototype \\
\hline 28 & Zhou et al. (2018) [54] & Conference & IoT & Ethereum & System architecture \\
\hline 29 & Arumugam et al. (2018) [55] & Conference & Supply chain & Ethereum & Prototype \\
\hline 30 & Stefanović et al. (2018) [56] & Conference & Public management & Ethereum, Hyperledger & Proposed method \\
\hline 31 & Islam and Kundu (2018) [57] & Conference & E-commerce & $\mathrm{N} / \mathrm{A}$ & Proposed method \\
\hline 32 & Hasan and Salah (2018) [58] & & ICT & Ethereum & Prototype \\
\hline 33 & Cruz et al. (2018) [59] & Journal & ICT & Ethereum & Prototype \\
\hline 34 & Niya et al. (2018) [60] & Conference & E-commerce & Ethereum & System architecture \\
\hline 35 & Fedosov et al. (2018) [61] & Conference & E-commerce & Ethereum & System architecture \\
\hline 36 & Pãnescu and Manta (2018) [62] & Journal & $\begin{array}{l}\text { Research data rights } \\
\text { management }\end{array}$ & Ethereum & Prototype \\
\hline 37 & Fotiou and Polyzos (2018) [63] & Conference & IoT & N/A & Proposed method \\
\hline 38 & de Souza et al. (2018) [64] & Conference & Public management & $\mathrm{N} / \mathrm{A}$ & $\begin{array}{l}\text { Theoretical } \\
\text { description }\end{array}$ \\
\hline 39 & Norta et al. (2018) [65] & Conference & Commercial property & $\begin{array}{c}\text { Ethereum, Hyperledger, } \\
\text { Qtum }\end{array}$ & System architecture \\
\hline 40 & Gu et al. (2018) [66] & Conference & Business & Ethereum & Proposed framework \\
\hline
\end{tabular}


TABle 2: Continued.

\begin{tabular}{|c|c|c|c|c|c|}
\hline No. & Author (year) & Source type & Application domains & Blockchain platform & Level of application \\
\hline 41 & Xu et al. (2018) [67] & Journal & IoT & Ethereum & Prototype \\
\hline 42 & Cheng et al. (2018) [68] & Conference & Education & Ethereum & System architecture \\
\hline 43 & Gatteschi et al. (2018) [69] & Journal & Insurance & Bitcoin & $\begin{array}{l}\text { Theoretical } \\
\text { description }\end{array}$ \\
\hline 44 & Król et al. (2018) [70] & Conference & ICT & Ethereum & System architecture \\
\hline 45 & Kim et al. (2018) [71] & Conference & ICT & Ethereum & Proposed framework \\
\hline 46 & Bedi et al. (2020) [72] & Conference & Education & Ethereum & Implementation \\
\hline 47 & Lamberti et al. (2018) [73] & Journal & Insurance & Ethereum & Prototype \\
\hline 48 & Omar and Basir (2018) [74] & Conference & IoT & Ethereum & Implementation \\
\hline 49 & Nayak et al. (2018) [75] & Conference & Cloud & Ethereum & System architecture \\
\hline 50 & Novikov et al. (2018) [76] & Conference & Healthcare & Ethereum & $\begin{array}{l}\text { Theoretical } \\
\text { description }\end{array}$ \\
\hline 51 & Uriarte et al. (2018) [77] & Conference & Cloud & Ethereum & Prototype \\
\hline 52 & Zhou et al. (2018) [78] & Conference & Cloud & Ethereum & Prototype \\
\hline 53 & Yu et al. (2018) [79] & Conference & Energy & Ethereum & Proposed framework \\
\hline 54 & Papadodimas et al. (2018) [80] & Conference & IoT & Ethereum & Implementation \\
\hline 55 & Jangir et al. (2019) [24] & Conference & Supply chain & Ethereum & Proposed framework \\
\hline 56 & Lyu et al. (2019) [81] & Conference & Voting & Ethereum & System architecture \\
\hline 57 & Pham et al. (2018) [82] & Conference & Healthcare & Ethereum & Prototype \\
\hline 58 & Augusto et al. (2019) [83] & Conference & Supply chain & Ethereum & Prototype \\
\hline 59 & Aleksieva et al. (2019) [84] & Conference & Finance & Ethereum & Prototype \\
\hline 60 & Le et al. (2019) [85] & Journal & E-commerce & Ethereum & Proposed framework \\
\hline 61 & Li et al. (2019) [86] & Conference & Public management & Ethereum & Proposed method \\
\hline 62 & Pittl et al. (2019) [87] & Conference & Business & Ethereum & Implementation \\
\hline 63 & Philipp et al. (2019) [88] & Journal & Supply chain & NA & $\begin{array}{l}\text { Theoretical } \\
\text { description }\end{array}$ \\
\hline 64 & Palma et al. (2019) [89] & Journal & Education & Ethereum & Prototype \\
\hline 65 & Kiran et al. (2019) [90] & Conference & ICT & Ethereum & Prototype \\
\hline 66 & $\begin{array}{c}\text { Manimaran and Dhanalakshmi } \\
\text { (2019) [91] }\end{array}$ & Conference & E-commerce & Ethereum & System architecture \\
\hline 67 & Pee et al. (2019) [92] & Conference & Energy & Ethereum & Prototype \\
\hline 68 & Wang et al. (2019) [93] & Journal & E-commerce & N/A & Proposed framework \\
\hline 69 & Luo et al. (2019) [94] & Conference & Construction & Hyperledger & Proposed framework \\
\hline 70 & Wu et al. (2019) [95] & Journal & E-commerce & Ethereum & Implementation \\
\hline 71 & Singla et al. (2019) [96] & Conference & Education & Ethereum & System architecture \\
\hline 72 & Nguyen et al. (2019) [97] & Conference & Public management & Ethereum & System architecture \\
\hline 73 & Liu et al. (2019) [98] & Journal & Electric vehicle & Ethereum & Proposed method \\
\hline 74 & Liu et al. (2019) [99] & Conference & Public management & Ethereum & System architecture \\
\hline 75 & Asfia et al. (2019) [100] & Conference & Electric vehicle & Ethereum & Proposed framework \\
\hline 76 & Pham et al. (2019) [101] & Conference & IoT & Ethereum & Prototype \\
\hline 77 & Neiheiser et al. (2019) [102] & Conference & Public management & Ethereum & Prototype \\
\hline 78 & dos Santos et al. (2019) [103] & Journal & Food manufacturing & Ethereum & Prototype \\
\hline 79 & Malan and Steyn (2019) [104] & Journal & Finance & N/A & $\begin{array}{l}\text { Theoretical } \\
\text { description }\end{array}$ \\
\hline 80 & Baharmand and Comes (2019) [105] & Journal & Supply chain & N/A & $\begin{array}{l}\text { Theoretical } \\
\text { description }\end{array}$ \\
\hline 81 & Wang et al. (2019) [7] & Journal & Finance & Hyperledger fabric & System architecture \\
\hline 82 & Nguyen et al. (2019) [106] & Conference & Finance & NEO & Proposed framework \\
\hline 83 & Yang et al. (2019) [107] & Conference & Finance & Ethereum & System architecture \\
\hline 84 & Duan et al. (2019) [108] & Journal & Electric vehicles & $\mathrm{N} / \mathrm{A}$ & Proposed method \\
\hline 85 & Giordanengo (2019) [109] & Journal & Healthcare & $\mathrm{N} / \mathrm{A}$ & $\begin{array}{l}\text { Theoretical } \\
\text { description }\end{array}$ \\
\hline 86 & Zaghloul et al. (2019) [110] & Conference & Healthcare & Ethereum & Proposed method \\
\hline 87 & Voutos et al. (2019) [111] & Conference & Agriculture & Ethereum & $\begin{array}{l}\text { Theoretical } \\
\text { description }\end{array}$ \\
\hline 88 & Zhang et al. (2019) [112] & Journal & Ride-hailing service & Ethereum & Prototype \\
\hline 89 & Hasan et al. (2019) [6] & Journal & Supply chain & Ethereum & Prototype \\
\hline 90 & Bader et al. (2018) [113] & Conference & Finance & Ethereum & Prototype \\
\hline 91 & Qu et al. (2019) [114] & Conference & Supply chain & Ethereum & Prototype \\
\hline 92 & Hanada et al. (2018) [115] & Conference & IoT & Ethereum & Prototype \\
\hline
\end{tabular}


TABle 2: Continued.

\begin{tabular}{|c|c|c|c|c|c|}
\hline No. & Author (year) & Source type & Application domains & Blockchain platform & Level of application \\
\hline 93 & Prause and Boevsky (2019) [116] & Journal & Supply chain & $\mathrm{N} / \mathrm{A}$ & $\begin{array}{l}\text { Theoretical } \\
\text { description }\end{array}$ \\
\hline 94 & Prause (2019) [117] & Journal & Supply chain & $\mathrm{N} / \mathrm{A}$ & $\begin{array}{l}\text { Theoretical } \\
\text { description }\end{array}$ \\
\hline 95 & $\begin{array}{l}\text { Asgaonkar and Krishnamachari. } \\
\text { (2019) [118] }\end{array}$ & Conference & E-commerce & $\mathrm{N} / \mathrm{A}$ & $\begin{array}{l}\text { Theoretical } \\
\text { description }\end{array}$ \\
\hline 96 & Chang et al. (2019) [119] & Journal & Supply chain & N/A & Proposed framework \\
\hline 97 & Koirala et al. (2019) [120] & Conference & Supply chain & Ethereum & Prototype \\
\hline 98 & Terzi et al. (2019) [121] & Conference & Supply chain & $\mathrm{N} / \mathrm{A}$ & Implementation \\
\hline 99 & Mohanta et al. (2019) [122] & Journal & IoT & Ethereum & Proposed framework \\
\hline 100 & Zhao et al. (2019) [123] & Journal & Entertainment & $\mathrm{N} / \mathrm{A}$ & System architecture \\
\hline 101 & Lin et al. (2019) [124] & Conference & Public management & Ethereum & Implementation \\
\hline 102 & Gong et al. (2019) [125] & Conference & Healthcare & Ethereum & Prototype \\
\hline 103 & Vidhyalakshmi et al. (2019) [126] & Journal & Real estate & Ethereum & Prototype \\
\hline 104 & Hasan and Salah (2019) [127] & Journal & ICT & Ethereum & Prototype \\
\hline 105 & Wang et al. (2019) [128] & Journal & Supply chain & Ethereum & Implementation \\
\hline 106 & Chang et al. (2019) [21] & Journal & International trade & Ethereum & Implementation \\
\hline 107 & Jaiswal et al. (2019) [129] & Conference & Agriculture & Ethereum & Proposed framework \\
\hline 108 & You et al. (2019) [130] & Conference & Energy & Ethereum & Proposed framework \\
\hline 109 & Yang et al. (2019) [131] & Conference & Healthcare & Ethereum & System architecture \\
\hline 110 & $\begin{array}{c}\text { Batista and Weingaertner (2019) } \\
\text { [132] }\end{array}$ & Conference & ICT & N/A & Proposed method \\
\hline 110 & Sheth and Subramanian (2019) [133] & Journal & Insurance & Ethereum & $\begin{array}{l}\text { Theoretical } \\
\text { description }\end{array}$ \\
\hline 112 & Putra et al. (2019) [134] & Conference & IoT & Ethereum & Implementation \\
\hline 113 & Kumar and Raja Kumar (2019) [135] & Journal & E-auction & Ethereum & Prototype \\
\hline 114 & Zhao and Wu (2019) [136] & Conference & Electric vehicles & $\mathrm{N} / \mathrm{A}$ & System architecture \\
\hline 115 & Jintapitak et al. (2019) [137] & Conference & Insect industry & $\mathrm{N} / \mathrm{A}$ & Proposed framework \\
\hline 116 & Wang et al. (2019) [138] & Journal & Energy & Ethereum & Implementation \\
\hline 117 & $\begin{array}{c}\text { Poptawski and Szczypiorski (2019) } \\
{[139]}\end{array}$ & Conference & Energy & N/A & Proposed method \\
\hline 118 & Bracciali et al. (2019) [140] & Conference & Public management & Ethereum & Prototype \\
\hline 119 & Mihelj et al. (2019) [141] & Journal & Public management & Ethereum & Prototype \\
\hline 120 & Ekici et al. (2019) [142] & Conference & ICT & Hyperledger fabric & Implementation \\
\hline 121 & Vinayak et al. (2019) [143] & Conference & Financial & Hyperledger fabric & Implementation \\
\hline 122 & Li and Liu (2019) [144] & Conference & Business & Ethereum & System architecture \\
\hline 123 & Li et al. (2019) [145] & Journal & Energy & Ethereum & Implementation \\
\hline 124 & Poorni et al. (2019) & Conference & Education & $\begin{array}{l}\text { Ethereum, Hyperledger } \\
\text { fabric }\end{array}$ & System architecture \\
\hline 125 & Qian et al. (2019) [147] & Conference & Digital resource copyrights & Hyperledger fabric & System architecture \\
\hline 126 & De Giovanni (2019) [148] & Journal & Supply chain & N/A & Proposed method \\
\hline 127 & Chen et al. (2019) [149] & Journal & Public management & $\mathrm{N} / \mathrm{A}$ & System architecture \\
\hline 128 & Bagozi et al. (2019) [150] & Conference & ICT & $\begin{array}{c}\text { Ethereum, Hyperledger } \\
\text { fabric }\end{array}$ & Proposed method \\
\hline 129 & oudoud et al. (2019) [151] & Conference & IoT & Ethereum & System architecture \\
\hline 130 & Kovalenko et al. (2019) [152] & Conference & Financial & Ethereum & System architecture \\
\hline 131 & Dai et al. (2019) [153] & Journal & Public management & Ethereum & Proposed framework \\
\hline 132 & Lin et al. (2019) [154] & Conference & Business & EOSIO & System architecture \\
\hline 133 & Nugraha et al. (2019) [155] & Conference & Public management & Hyperledger fabric & System architecture \\
\hline 134 & Montes et al. (2019) [156] & Conference & Supply chain & Hyperledger fabric & Proposed framework \\
\hline 135 & Omar et al. (2019) [157] & Conference & Healthcare & Ethereum & Proposed method \\
\hline 136 & Avizheh et al. (2019) [158] & Conference & ICT & Ethereum & Implementation \\
\hline 137 & Le and Mutka (2019) [159] & Conference & IoT & Ethereum & Prototype \\
\hline 138 & Khatoon (2020) [8] & Journal & Healthcare & Ethereum & Implementation \\
\hline 139 & Kumar et al. (2020) [160] & Conference & Land transaction & Ethereum & System architecture \\
\hline 140 & Wang et al. (2020) [161] & Journal & ICT & $\mathrm{N} / \mathrm{A}$ & System architecture \\
\hline 141 & Dorsala et al. (2020) [162] & Journal & ICT & Ethereum & Implementation \\
\hline 142 & Yu et al. (2020) [163] & Journal & Food manufact & Ethereum & Prototype \\
\hline 143 & Neiheiser et al. (2020) [164] & Journal & Public management & Ethereum & Prototype \\
\hline
\end{tabular}


TABLE 2: Continued.

\begin{tabular}{|c|c|c|c|c|c|}
\hline No. & Author (year) & Source type & Application domains & Blockchain platform & Level of application \\
\hline 144 & $\begin{array}{c}\text { Chong and Diamantopoulos (2020) } \\
\text { [23] }\end{array}$ & Journal & Construction & Hyperledger & System architecture \\
\hline 145 & Chen et al. (2020) [165] & Journal & ICT & N/A & Proposed method \\
\hline 146 & Wang et al. (2020) [166] & Journal & Electric vehicles & Multiple platforms & Implementation \\
\hline 147 & Patel and Das (2020) [167] & Conference & Education & Hyperledger & Prototype \\
\hline 148 & Nakamura et al. (2020) [168] & Journal & IoT & Ethereum & Prototype \\
\hline 149 & Shahab and Allam (2019) [169] & Journal & Public management & N/A & $\begin{array}{l}\text { Theoretical } \\
\text { description }\end{array}$ \\
\hline 150 & Sultana et al. (2020) [170] & Journal & IoT & Ethereum, Spyder & Prototype \\
\hline 151 & Debe et al. (2020) [171] & Journal & ICT & Ethereum & Implementation \\
\hline 152 & Elghaish et al. (2020) [11] & Journal & Construction & Hyperledger & Implementation \\
\hline 153 & Han et al. (2020) [172] & Journal & Energy & Ethereum & System architecture \\
\hline 154 & Xuan et al. (2020) [173] & Journal & Data sharing & $\mathrm{N} / \mathrm{A}$ & Proposed method \\
\hline 155 & Fu et al. (2020) [174] & Journal & Electric vehicle & Ethereum & Implementation \\
\hline 156 & Matai et al. (2020) [175] & Journal & Real estate & Ethereum & Prototype \\
\hline 157 & Vyas et al. (2020) [176] & Conference & Healthcare & Ethereum & Implementation \\
\hline 158 & Jamil et al. (2020) [177] & Journal & Healthcare & Hyperledger fabric & Implementation \\
\hline 159 & Prashar et al. (2020) [178] & Journal & Supply chain & Ethereum & Prototype \\
\hline 160 & Reniers et al. (2020) [179] & Conference & Data sharing & Ethereum & Implementation \\
\hline 161 & Kurnia et al. (2020) [180] & Conference & Supply chain & N/A & System architecture \\
\hline 162 & Habib et al. (2020) [181] & Conference & Supply chain & $\mathrm{N} / \mathrm{A}$ & Proposed framework \\
\hline 163 & Neysen (2020) [182] & Journal & Recording industry & N/A & $\begin{array}{l}\text { Theoretical } \\
\text { description }\end{array}$ \\
\hline 164 & Zghaibeh et al. (2020) [183] & Journal & Healthcare & Hyperledger fabric & System architecture \\
\hline 165 & Luchoomun et al. (2020) [184] & Journal & Automotive industry & Hyperledger fabric & Implementation \\
\hline 166 & Chiacchio et al. (2020) [185] & Journal & Pharma industry & Ethereum & Prototype \\
\hline 167 & Makmur et al. (2020) [186] & Journal & Energy & Ethereum, bitcoin & System architecture \\
\hline 168 & Gong et al. (2020) [187] & Conference & IoT & Ethereum & Implementation \\
\hline 169 & Pertiwi et al. (2020) [188] & Journal & Entertainment & Ethereum & $\begin{array}{l}\text { Theoretical } \\
\text { description }\end{array}$ \\
\hline 170 & Adrian et al. (2020) [189] & Jour & E-logist & N/ & Proposed framework \\
\hline 171 & Gürsoy et al. (2020) [190] & Journal & Healthcare & Ethereum & Prototype \\
\hline 172 & Shurman et al. (2020) [191] & Conference & IoT & Ethereum & Proposed framework \\
\hline 173 & Gupta et al. (2020) [192] & Confer & Financial & $\mathrm{N} /$ & $\begin{array}{l}\text { Theoretical } \\
\text { description }\end{array}$ \\
\hline 174 & Panja et al. (2020) [193] & Journal & E-voting & Ethereum & Implementation \\
\hline
\end{tabular}

4.2. Journals. Among the 174 selected publications, 102 were from conferences, and 72 were from journals. As shown in Figure 3, the 72 journal papers come from 53 journals, reflecting a wide variety of multidisciplinary sources. Of these, eight journals had published at least two articles, such as automation in construction, sensors, IEEE Access, etc. The rest published one per journal.

4.3. Analysis of Collaborative Networks of Authors, Institutions, and Countries. The visualized collaboration network can reflect, to a certain extent, the closeness of research collaboration among authors, institutions, and countries. It also allows us to track some of the major research institutions and authors quickly. The authors' collaboration network is shown in Figure 4. 606 authors have researched on this topic. However, only two authors have published more than three papers, Salah K. (5 papers) and Prause G. (3 papers). The percentage of authors who published only one paper was $93.7 \%$. That indicates that the current research on the application of smart contracts in various industries is still in the primary stage. Few scholars have published many publications, and cooperation between authors is lacking. For example, the scholar with the most collaborative connections, Salah K., had a total link strength of only twelve.

The collaboration network among institutions is shown in Figure 5. A total of 238 institutions have researched this topic, most of which have published only one paper. Only nine institutions have published more than three papers, among which Tsinghua University and Khalifa University have published the most, each with four papers. As can be seen from the figure, there are few links and cooperation between institutions. Among them, National University of Singapore, Tsinghua University, and University of Aizu have many links with other institutions, but the number of links of each is only five.

Meanwhile, this argument is also supported by the network of cooperation between countries. In Figure 6, each node represents a country, and its size reflects the number of papers contributed by authors from that country. China is the country with the largest number of published papers (47 papers), followed by India (24 papers). The United States, United Kingdom, and Italy have published a few articles as well. It is noteworthy that the United States, while not the 

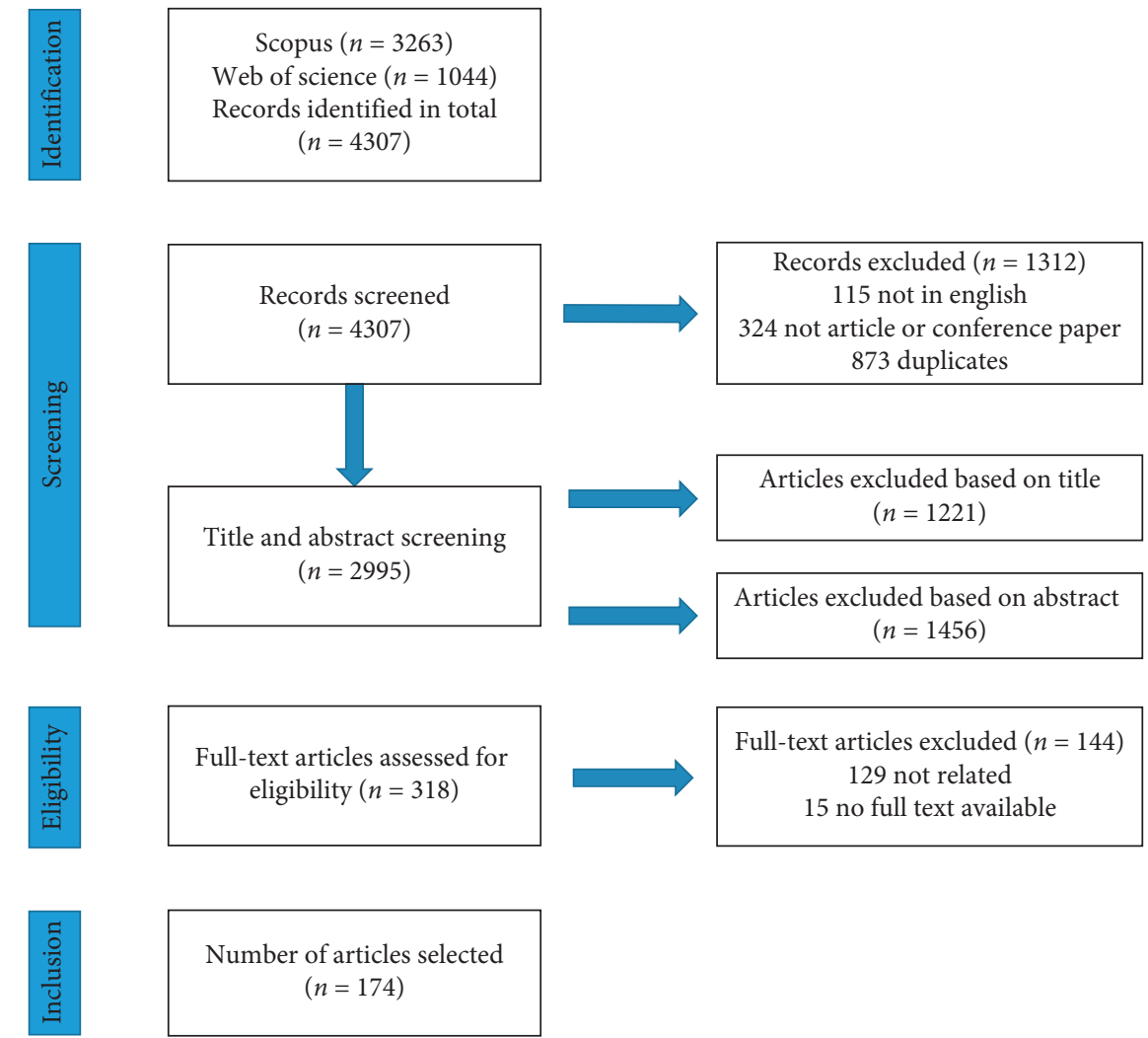

Figure 1: Overall flow of the review process and strategy.



Figure 2: Paper distribution by year of publication.

most publishing country, is the most cited, with $1,329 \mathrm{ci}-$ tations. The links in Figure 6 denote the collaboration between countries, and their thickness explains the collaboration strength between the two countries. For example, China researchers had established a network of collaboration with twelve countries across the world, followed by the United Kingdom with seven countries. Although some links have been established at the national level, there is still room for improvement.
4.4. Cooccurrence Analysis of Keywords. To construct the knowledge domains of smart contracts applications in various industries, a keyword cooccurrence analysis was performed on the selected publications using VOS viewer. Choose network visualization to present the results of bibliometric analysis on smart contracts applications literature. The output of the VOS viewer is a distance-based map, where the distance between two keywords reflects the strength of the relationship between the keywords. A smaller distance usually indicates a stronger relationship. The size of the keyword label reflects the number of publications where the keyword was found. The larger the size of the keyword label, the more publications are containing the keyword. Different colors represent different keywords' groups that clustered by the clustering technology of VOS viewer. The information of 174 publications obtained from Scopus and Web of Science databases was input into the VOS viewer. Set the threshold of keyword occurrences to four to improve the representativeness and comprehensiveness of the clustering results. As a result, 54 of the 1336 keywords reached the threshold. In Figure 7, the cooccurrence keywords are grouped into five clusters with various colors. Cluster 1 (red) refers to the blockchain, with primary keywords including trusted third parties, transparency, cost, finance, game theory, and contracts; cluster 2 (green) refers to the Internet of Things, with primary keywords including digital storage, privacy, data sharing, information management, trust, privacy, automation, and healthcare; cluster 3 (blue) refers to smart contract and commerce, with primary keywords 


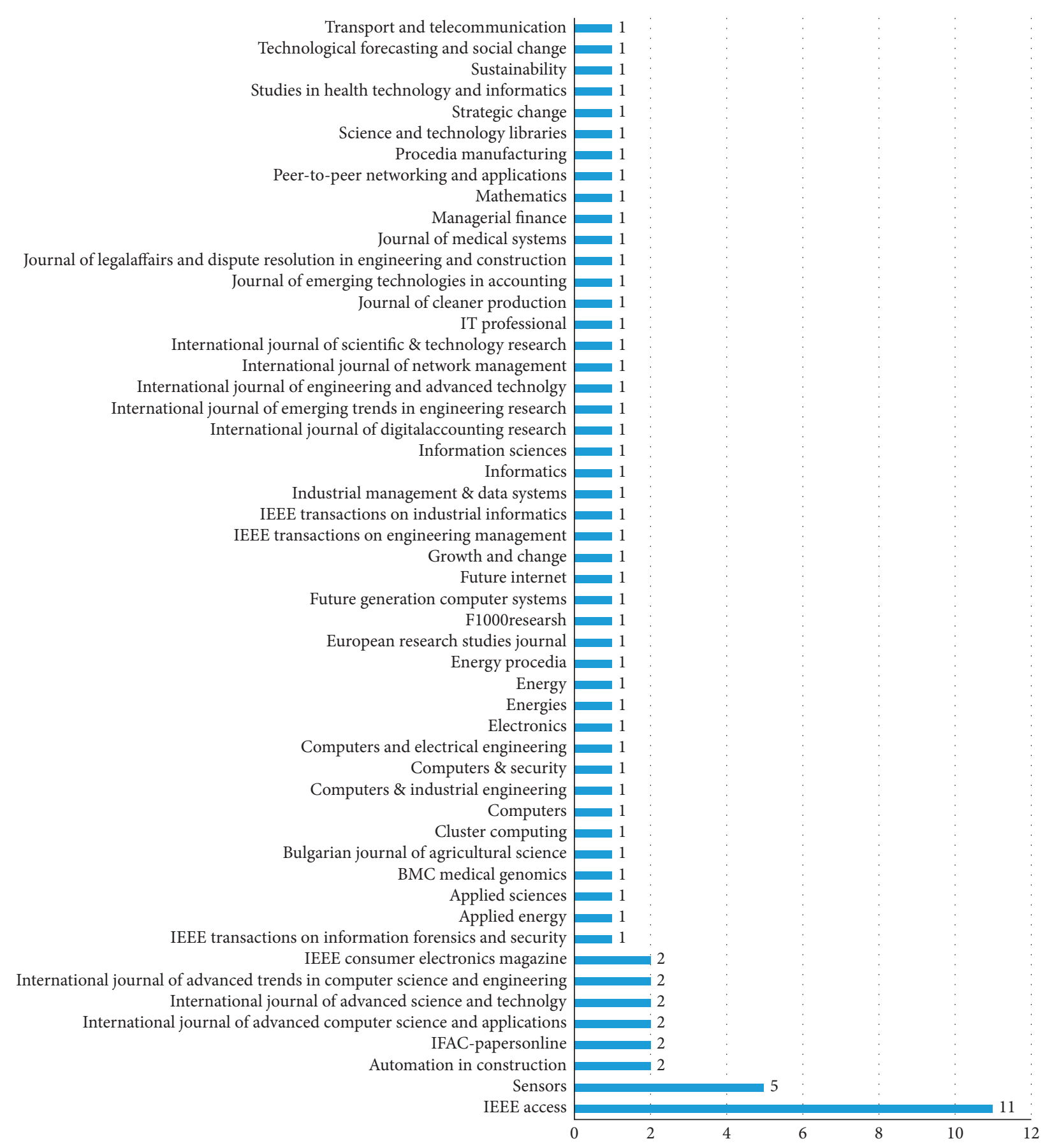

FIGURE 3: Journal/conference publications and number of papers published.

including electric vehicle, transaction process, decentralization, energy trading, artificial intelligence, and peerto-peer networks; cluster 4 (yellow) refers to security, with primary keywords including data privacy, identity management, green computing, access control, and insurance; cluster 5 (purple) refers to supply chain, with primary keywords including Ethereum and logistics.

Table 3 lists the detailed quantity information of the popular keywords in Figure 7 (all greater than nine). The occurrences show the number of occurrences of each keyword from the keywords retrieved from the selected publication. For instance, except for the keyword blockchain and smart contract, the Internet of Things, Ethereum, trusted third parties, and supply chain are the most frequently occurring keywords, which shows that they have been extensively studied in existing research. The average year published shows the average time period in which a given keyword has been investigated by researches. For example, keywords Internet of Things, Ethereum, and commerce received more attention around 2018, while research on supply chain, data storage, access control, and healthcare had the greatest publication frequency in 2019. 
on vosviewer

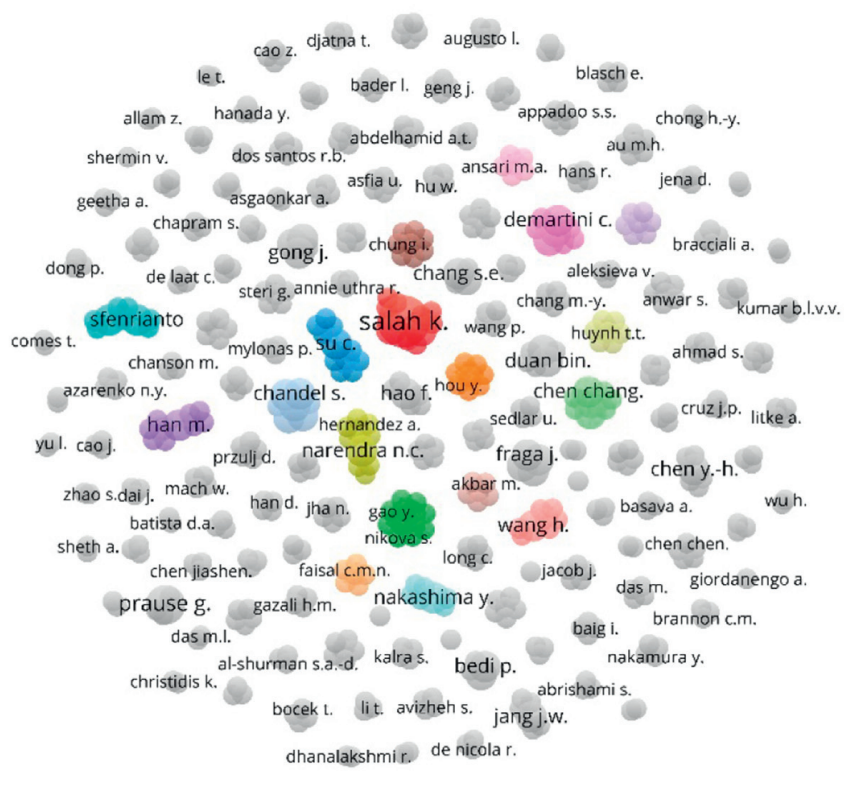

FiguRE 4: A collaborative network of authors.

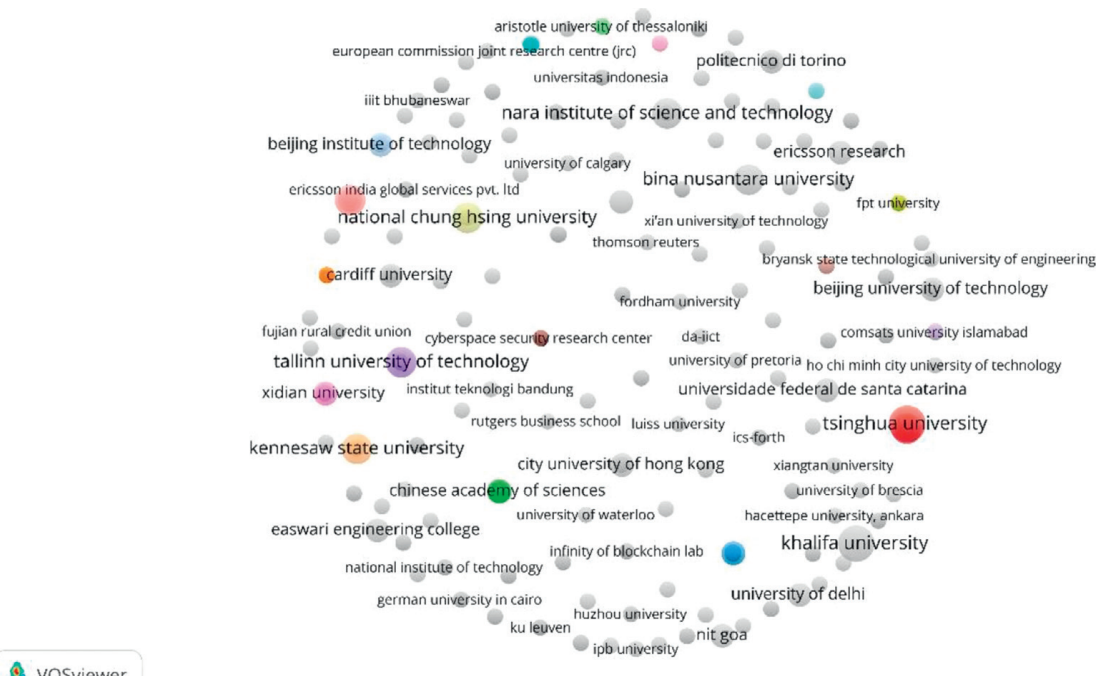

FIgURE 5: A network of cooperation between institutions.

That indicates that the latter represents an emerging topic in the research of smart contracts applications in various industries. Links are the number of links between a given keyword and others, while the total link strength reflects the total strength linked with a specific keyword. For example, the total link strength of supply chain is 74 , which is at the high level of all the keywords and shows the strong interrelatedness between supply chain and smart contract.

4.5. Citation Analysis. Since citations are considered a vital indicator of the paper's impact, a citation analysis was conducted to determine the degree of acceptability for this field research. Table 4 shows the 10 most frequently cited publications. The most cited publication is [28], with 2,545 citations. It focuses on integrating blockchain and IoT and points out that the combination of blockchain and the Internet of Things can bring significant changes to many industries. That also demonstrates that the combination of blockchain and smart contracts with IoT has received extensive attention from scholars. The second most cited publication is [31], with 291 citations. It introduces a decentralized and self-tallying Internet voting protocol with maximum voter privacy using blockchain and smart contract. The third most cited publication is [53], with 241 citations. It proposes utilizing blockchain-based smart contracts to facilitate the security analysis and management of medical sensors. Apart from that, we also analyze cocited 


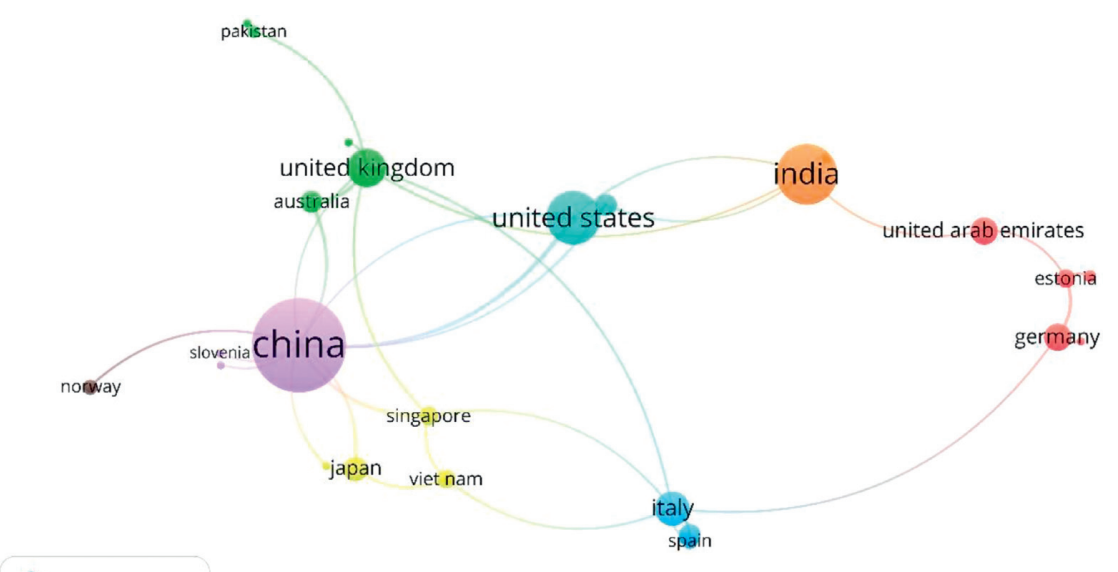

S vosviewer

FIgURE 6: A network of cooperation between countries.

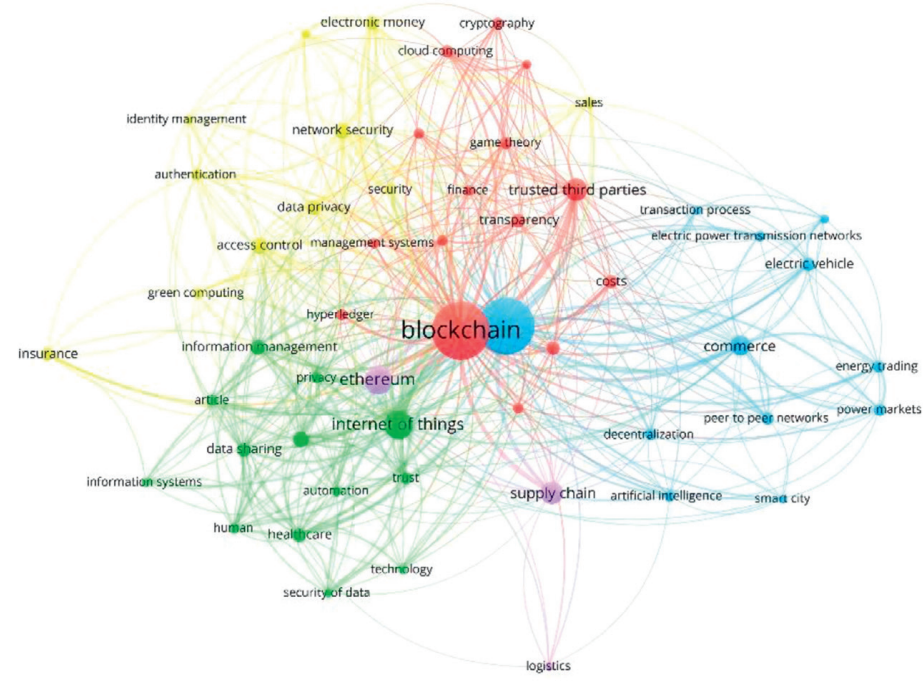

A vosviewer

FIgURE 7: Keywords cooccurrence network.

TABLe 3: Top keywords in smart contracts applications literature.

\begin{tabular}{|c|c|c|c|c|}
\hline Keywords & Occurrences & Average year published & Links & Total link strength \\
\hline Blockchain & 155 & 2018.83 & 53 & 548 \\
\hline Smart contract & 148 & 2018.84 & 53 & 516 \\
\hline Internet of Things & 38 & 2018.61 & 42 & 171 \\
\hline Ethereum & 36 & 2018.61 & 36 & 153 \\
\hline Trusted third parties & 23 & 2018.96 & 36 & 111 \\
\hline Supply chain & 23 & 2019.13 & 22 & 74 \\
\hline Commerce & 18 & 2018.50 & 27 & 77 \\
\hline Digital storage & 12 & 2019.00 & 20 & 50 \\
\hline Network security & 11 & 2018.73 & 26 & 58 \\
\hline Access control & 11 & 2019.09 & 25 & 56 \\
\hline Data privacy & 10 & 2018.80 & 25 & 57 \\
\hline Information management & 10 & 2018.80 & 21 & 46 \\
\hline Healthcare & 9 & 2019.22 & 22 & 46 \\
\hline Electronic money & 9 & 2018.67 & 17 & 42 \\
\hline Data sharing & 9 & 2019.22 & 19 & 41 \\
\hline Transparency & 9 & 2019.11 & 18 & 37 \\
\hline
\end{tabular}


TABLE 4: The top 10 cited articles.

\begin{tabular}{|c|c|c|c|}
\hline No. & Author and year & Title & Total citations \\
\hline 1 & $\begin{array}{l}\text { Christidis and Devetsikiotis } \\
\text { (2016) [28] }\end{array}$ & Blockchains and smart contracts for the Internet of Things & 2545 \\
\hline 2 & McCorry et al. (2017) [31] & A smart contract for boardroom voting with maximum voter privacy & 291 \\
\hline 3 & Griggs et al. (2018) [53] & $\begin{array}{l}\text { Healthcare blockchain system using smart contracts for secure automated remote } \\
\text { patient monitoring }\end{array}$ & 241 \\
\hline 4 & Gatteschi et al. (2018) [69] & Blockchain and smart contracts for insurance: Is the technology mature enough? & 224 \\
\hline 5 & Shermin (2017) [40] & ernance with blockchains and smart contracts & 152 \\
\hline 6 & Nugent et al. (2016) [29] & Improving data transparency in clinical trials using blockchain smart contracts & 142 \\
\hline 7 & Bogner et al. (2016) [27] & $\begin{array}{l}\text { A decentralized sharing app running a smart contract on the Ethereum } \\
\text { blockchain }\end{array}$ & 137 \\
\hline 8 & Cruz et al. (2018) [59] & RBAC-SC: Role-based access control using smart contract & 119 \\
\hline 9 & Hahn et al. (2017) [36] & $\begin{array}{l}\text { Smart contract-based campus demonstration of decentralized transactive energy } \\
\text { auctions }\end{array}$ & 97 \\
\hline 10 & Hasan and Salah (2019) [127] & Combating deepfake videos using blockchain and smart contracts & 92 \\
\hline
\end{tabular}

authors in selected publications, as this helps researchers quickly locate key scholars and articles in the area. Figure 8 reports the visualization of cocited authors, where the minimum number of citations for an author is set to 10 , and the total link strength is set to 100 . Node size is proportional to the number of citations, and different colors represent different clusters. Satoshi Nakamoto is one of the pioneers in smart contract research. Unsurprisingly, he is the most cocited scholar.

4.6. Application Industry, Level of Application, and Platform. Figure 9 shows the classification of application of smart contracts in various industries. It can be categorized into 12 industries. The industries from information communication technology (ICT), public governance, supply chain, energy, business, finance, and healthcare accounted for $85.63 \%$. In other words, they are the major industries smart contract applied in.

In the selected publications, 62 publications (35.63\%) focused on theoretical descriptions or proposed frameworks/methods and 76 publications $(43.68 \%)$ were related to abstract prototyping or implementation of smart contracts. Although the papers from the abstract prototyping or implementation made up a larger proportion, there were not many practical applications or cases yet, indicating that the development of smart contracts is still in the preliminary stage of exploration. Besides, Ethereum and Hyperledger fabric were the leading technology for smart contract applications in various industries, as most of the smart contracts were hosted on these platforms.

\section{Results of the Systematic Review}

In this section, we attempt to answer RQ2 and RQ3.

5.1. RQ2. What Are the Benefits of Smart Contracts Applications in Various Industries from the Procurement Perspective? By comparing and analyzing selected publications, we summarized the main benefits of smart contracts in various industries (see Table 5). Besides, we also compared the benefits of smart contracts in different industries, as shown in Table 6.

Smart contracts have many advantages for a wide range of potential applications that could benefit business transactions and management across industries. In principle, smart contracts do not rely on any human interventions, and their implementations are guided and overseen by other nodes in the blockchain network. Once the contract is triggered, the scripted contract will self-execute and proceed to the next transaction. In this way, smart contracts can increase the speed of a wide variety of business processes and greatly reduce turnaround time. For example, Chong and Diamantopoulos [23] demonstrated that smart contracts' automatic execution function solves the delayed payment in the construction industry. Nugraha et al. [155] highlighted that smart contracts address high cycle time and low activity time efficiency in official documents business process. Aleksieva et al. [84] articulated that smart contracts can reduce operational costs and time to process claims for losses in the insurance industry.

Automated transactions are not only faster but also less error prone. The automation exhibit in smart contracts avoids most of the wastes and issues found in traditional contracts. Stefanović et al. [56] mentioned that smart contracts could improve the transaction registration process and eliminate the possibility of "double spending" in land administration systems. Hasan et al. [6] underlined that smart contracts could be used to manage shipment conditions, automate payments, legitimize receiver, and issue a refund if violating the predefined conditions. Shahab and Allam [169] indicated that using smart contracts can lower the transaction costs of tradable permission programs. Khatoon [8] mentioned that smart contracts could simplify the transaction process in the healthcare industry and thus reduce the management burden and cut down transaction costs.

Since the terms and conditions of the contract become explicitly visible to participants involved in the specific blockchain, transparency and trust are facilitated, and fraud issues are eliminated. Wang et al. [93] stated that smart contracts could enhance transaction transparency in the 
A vosviewer

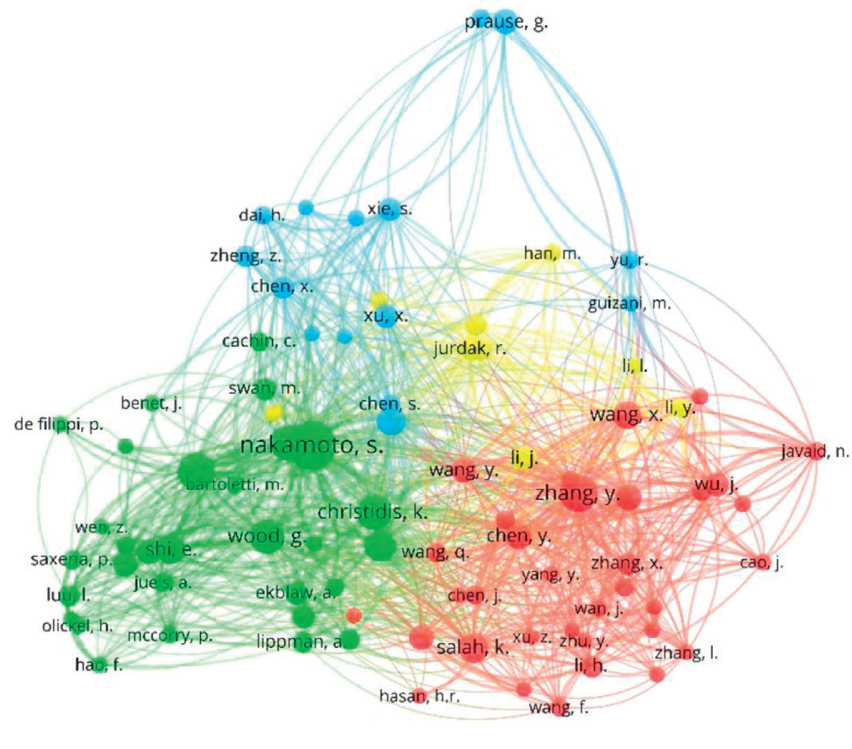

Figure 8: Cocitation authors analysis.

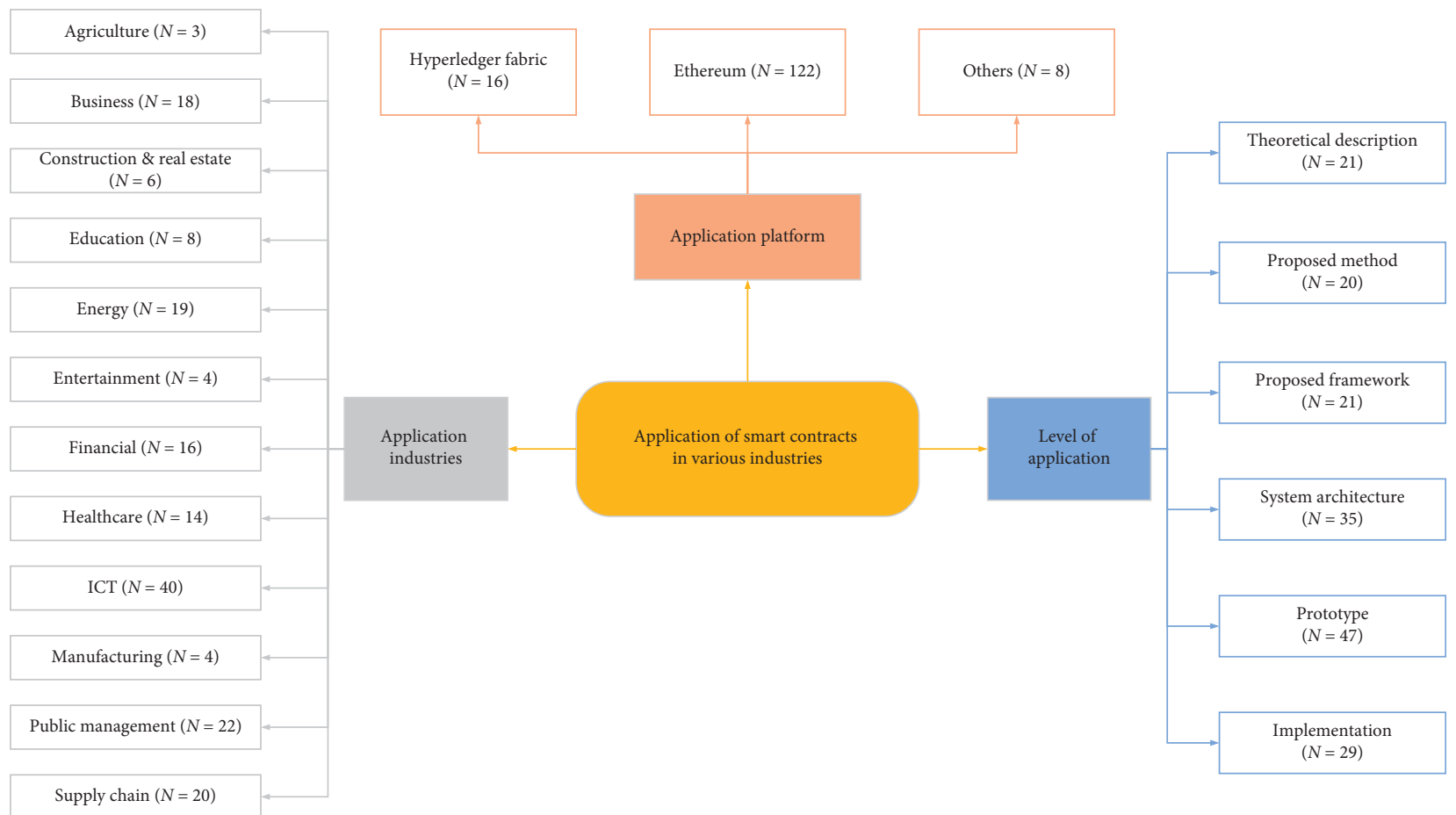

FIGURE 9: Classification of the application of smart contracts in various industries.

consumer electronics industry and reduce fraud. Neiheiser et al. [164] revealed that smart contracts could improve the transparency and reliability of the recruitment process, further increasing the likelihood of a fair selection process. Zhao and O'Mahony [50] stated that, with smart contracts, music rights holders could automatically receive royalty payments from the music industry rather than relying on intermediaries. Gu et al. [66] considered that smart contracts could guarantee information and privacy security in the crowdsourcing process at a lower cost without the participation of trusted third-party institutions. Jaiswal et al. [129] indicated that smart contracts could better return to farmers by reducing the overall cost at the end-user side through removing intermediaries.

Smart contracts have privacy protection and tamperproof functions. Contracts implemented in an encrypted manner could enhance the security of the transaction and thwart any malicious activity that may alter the execution 
TABLE 5: Benefits of utilizing smart contracts in various industries.

Industry domain

Agriculture [111, 129, 137]

Business [21, 27, 49, 57, 60, 61, 65, $66,85,87,91,93,95,112,118$, $135,144,154]$

Construction \& real estate $[11$, $23,41,94,126,175]$

Education [35, 62, 68, 72, 89, 96, $146,167]$

Energy [32, 34, 36, 44, 51, 79, 92, $98,100,108,130,136,138,139$, $145,166,172,174,186]$

Entertainment [50, 123, 182, 188]

Financial $[7,33,43,47,48,69,73$, $84,104,106,107,113,133,143$, $152,192]$

Benefits

Improve product quality and the associated supply chain and agricultural logistics [111]

Reduce costs, eliminate intermediaries, increase transparency and safety [129]

Automatic execution agreement, safe and real-time transactions, product traceability [137]

Eliminate the need for a trusted third party $[27,49,61,65,66,91,95,112,118,135,144]$

Avoid the bid price leaked by the lead bidder [49]

Preserve privacy $[27,57,60,66,76]$

Ensure time-efficient and secure transactions $[60,112]$

Provide cost reductions, faster transaction times, greater transparency, and reduced regulatory burdens [65]

Prevent fraud $[85,118]$

Improve the efficacy of transactions and prevent counterfeiting electronics trading [93]

Ensure the integrity and transparency and tamper-safe negotiation process [87]

Prevent bidder collusion [95]

Mitigate endeavors spent on manual manipulation and confirmation [21, 144]

Ensure the agreements will not be breached [154]

Automate construction payments [41, 94]

Provide more secured and transparent transactions [23, 175]

Record and monitor transactions without the need for of a trusted third party [126]

Execute all financial transactions automatically [11]

Solve the issue of default payments of study loans [35]

Promote research data rights management [62]

Provide accurate and reliable information on digital certificates $[68,72]$

Decrease bureaucracy in terms of document validation, saving in storage and labor [72, 89]

Manage leave applications and prevent corruption [96]

Prevent forgery of certificates [146]

Improve transcript management [167]

Automated negotiation, settlement, and payment $[32,136]$

Eliminate the need for a trusted entity oversight $[34,36,44,79]$

Protect the data privacy of transactions $[44,100]$

Improve the security and completeness of the transaction $[51,108,172]$

Ensure the fairness, transparency, and immutability of the transaction $[79,92,98,139,145,166,172$, $174,186]$

Automate execution without third-party intervention [92, 98, 130, 139, 145, 166, 172]

Energy demand management [138]

Substitute for written contracts and save file storage space [186]

Improve music copyright protection [50]

Provide digital rights management $[123,182]$

Provide instant payment, eliminate some intermediaries [182, 188]

Lower execution risk, reduce the number of insurance intermediaries [33]

Predict for market conditions [43]

Automate insurance payment, privacy protection [47]

Improve audit quality [48]

Speed up insurance claims processing and reduce operating costs $[69,84,106,113,133]$

Lower policy modification costs and limit insurance fraud [73]

Reduce manual labor and back-office workloads as well as the removal of reconciliation and corporate actions [104]

Improve the transparency, security, and traceability for the loan business [7]

Improve the problems of insufficient supervision ability and low loan efficiency in the transaction process [107]

Decrease information asymmetry [133]

Automate transaction execution without intermediary $[143,152]$

Reduce the possibility of corruption and embezzlement [152]

Reduce corporate frauds [192] 
TABle 5: Continued.

Industry domain
Healthcare $[8,29,53,76,82,109$,
$110,125,131,157,176,177,183$,
$190]$

ICT $[28,30,38,42,45,46,54,58$, $59,63,67,70,71,74,75,77,78$, $80,90,101,115,122,127,132$, $134,142,150,151,158,159,161$, $162,165,168,170,171,173,179$, $187,191]$

Manufacturing [103, 163, 184, 185]

Public management [31, 39, 40, $52,56,64,81,86,97,99,102,124$, $140,141,147,149,153,155,160$, $164,169,193]$

Supply chain $[6,24,37,55,83,88$, $105,114,116,117,119-121,128$, $148,156,178,180,181]$
Benefits

Improve data transparency in clinical trials $[29,157]$

Secure automated remote patient monitoring [53, 82, 177]

Improve the security and privacy of electronic medical records $[76,110,131]$

Protect patient privacy $[82,125,176,183]$

Improve data sharing $[109,176,183]$

Simplify procedures, reduce transaction costs, reduce administrative burdens, and remove intermediaries [8]

Reduce query pharmacogenomics data time [190]

Automate complex multistep processes $[28,46,58,70,75,132,142,171,187,191]$ Improve IoT services $[54,71,80,115,191]$

Improve information and security management [63] Access control [59, 67, 90, 134, 168, 170]

Improve identity management [30, 74, 165, 179]

Enhance the security of IoT data sharing management [71, 101, 151, 170] Increase the security and privacy $[122,159]$

Reduce the turnaround time of transactions without third party $[38,173]$

Improve trust in the cloud $[42,75,77,78,150]$

Safer mobile payment [45]

Combat deepfake videos [127]

Promote a verifiable computation $[158,162]$

Provide public cloud storage auditing [161] Improve data sharing $[173,179]$

Utilize the autoexecution to achieve reliable and efficient quality monitoring [163]

Implement a consumer trustworthy ingredient certification scheme [103]

Enhance trust and traceability, prevent tampering with vehicle information and mileage [184] Improve and strengthen the traceability process [185]

Protect the voter's privacy [31, 81]

Make testament tamper-proof, secure, transparent [39]

Reduce transaction cost and bureaucracy [40, 169]

E-waste management [52]

Improve the process of registering transactions in the land administration system $[56,160]$ Reduce corruption [64, 149]

Eliminate a trusted third party [81, 97, 140, 169, 193]

Manage value-added tax payment [97]

Enable secure and privacy-preserving identity management [99]

Reduce the required workforce needed for the recruitment selection process and add more transparency and trust $[102,164]$

Ensure the unique data source of government data resources [124]

Provide traffic event detection and source reputation assessment [141]

Realize digital resource copyrights transactions and protection [147] Avoid malicious and false payment [149]

Automate routine audit processes [153]

Improve official document management [155]

Increase transparency and trust $[24,37,55,83,105,119,156,180]$

Monitor products and automate the tracking and clearance processes $[6,24,55,83,114,121,128$, 178]

Improve quality management and demand-supply management [24]

Reduce intermediaries, transaction costs, and time $[6,88,114,116,117,156,178]$

Manage shipment conditions, automate payments $[6,116]$

Improve business process reengineering across enterprise borders $[116,117,119]$

Streamline the administrative processes and automatize the transactions $[120,148,181]$ sequence or execute invalid transactions. Niya et al. [60] pointed out that the application of smart contracts can secure users' privacy and transactions. Giordanengo [109] pointed out that smart contracts may be an effective way to solve the security and privacy challenges in the healthcare industry. Han et al. [172] underlined that as smart contracts strictly execute the trading and payment rules without artificial intervention, the security and fairness of energy trading are significantly enhanced.

Based on the above analysis and Table 6, some smart contracts' benefits are universal in different industries, such as trust, transparency, traceability, elimination or reduction of intermediaries, secure transactions, privacy protection, simplification of transaction processes, reduction of human 
TABle 6: Comparison of smart contract benefits in different industries.

\begin{tabular}{|c|c|c|c|c|c|c|c|c|c|c|c|c|}
\hline \multirow{2}{*}{ Industry } & \multicolumn{12}{|c|}{ Benefit } \\
\hline & 1 & 2 & 3 & 4 & 5 & 6 & 7 & 8 & 9 & 10 & 11 & 12 \\
\hline Agriculture & $\bullet$ & $\bullet$ & - & - & - & & & & • & - & & 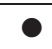 \\
\hline Busin & - & - & & - & e & - & & - & - & & & - \\
\hline $\begin{array}{l}\text { Construction \& real } \\
\text { estate }\end{array}$ & & - & & & & & & & - & - & & \\
\hline Education & & & & & 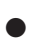 & - & $\bullet$ & - & & & & \\
\hline Ener & ○ & - & & 0 & 0 & • & & & & - & & 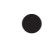 \\
\hline Ente & & & &  & & • & & & & & & \\
\hline ina & $\bullet$ & 0 & $\bullet$ & - & 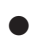 & - & 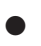 & $\bullet$ & • & $\bullet$ & & \\
\hline Healthcare & & - & & - & & - & & 0 & - & - & $\bullet$ & • \\
\hline $\mathrm{CT}$ & $\bullet$ & & $\bullet$ & $\bullet$ & $\bullet$ & $\bullet$ & & $\bullet$ & & & $\bullet$ & $\bullet$ \\
\hline Manul & 0 & & 0 & & & & & & & & & \\
\hline anagement & - & - & & 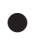 & - & 0 & • & ○ & - & $\bullet$ & & \\
\hline Supply chain & - & & & & • & & & & & - & & \\
\hline
\end{tabular}

Note: $1=$ Trust, $2=$ Transparency, $3=$ Traceability, $4=$ Eliminate or reduce intermediaries, $5=$ Secure transaction, $6=$ Privacy protection, $7=$ Prevent corruption, $8=$ Simplify the process, $9=$ Reduce costs, $10=$ Reduce human error, $11=$ Data sharing, 12 = Time-efficient.

error, and time saving. However, some industries have specific advantages, such as education, finance, and public management, where smart contracts have the potential to reduce corruption. The emergence of smart contracts reduces the possibility of corruption and embezzlement in distributing and transferring funds of the main organization between its instances. The integration of blockchain and smart contracts can prove the identity of bidders and bidding entities, automate the bidding process, and provide audit and audit support. Smart contracts also provide a solution for electronic voting systems, ensuring the fairness of the voting and personnel recruitment process. They provide barriers to fraud and corruption in public procurement. In the healthcare and ICT industries, improving data sharing is its unique advantage. Data sharing is the key support for the scale application of the Internet of Things. Blockchain-based smart contracts can provide a decentralized, secure, efficient, low-cost, and extensible distributed framework for data sharing in the Internet of Things. The healthcare industry has always been faced with the issue of data sharing. By setting access rights through smart contracts, users can achieve efficient and safe peer-to-peer data sharing without worrying about data leakage and tampering, and data reliability is fully guaranteed.

5.2. RQ3. What Are the Potential Advantages of Smart Contracts in the Procurement Process? There are many intermediaries in traditional procurement processes that hinder the overall procurement performance's efficiency [21]. Smart contracts then have opened a new procurement method that enhances trust and transparency between transaction parties while reducing or eliminating intermediaries. That will increase operational efficiency through a more efficient way of contracting in the procurement process. From the procurement process perspective, three main impact areas have been identified from the current development and application of smart contracts, such as supplier management, contract management, and logistics management, as shown in Table 7.

First, from the supplier management aspect, evaluation indicators/requirements of suppliers could be written into smart contracts. For example, the credit rating could be carried out to help select the appropriate supplier. Smart contracts could handle all bidding transactions without a third party [91], and this tamper-proof function helps ensuring transparency and fairness as well as preventing bidder collusion and corruption in the bidding process [79, 95]. Moreover, the trust and transparency provided by smart contracts could further improve the relationship between suppliers and promote collaboration and mutual benefit between suppliers.

Second, regarding the contract management aspect, smart contracts could be a platform to ensure integrity and transparency during multiround bilateral negotiations, where buyers and suppliers could exchange their offers in an effective and trustworthy manner [87]. More importantly, smart contracts could reduce the effort spent on manual operation and confirmation, which greatly reduce workloads and disputes occurring in paper contracts [106]. Furthermore, smart contracts could also fully automate contract management via enabling instantaneous transactions payment from buyers to suppliers [11, 181]. That not only shortens the cash payment cycle but also eliminates human errors, overpayments, and duplicate payments.

Regarding the logistics management aspect, smart contracts could track procurement workflows (notably decisions and documentation), strengthen trails immutability, and provide real-time traceability of irregularities [128]. For example, the combination of smart contracts and the Internet of Things could play a complimentary role for product monitoring, tracking, and clearing [55]. Moreover, all interactions, communications, and transactions in the supply chain network between all stakeholders could be monitored and managed $[6,178]$.

\section{Discussion and Framework}

The review has identified many applications of smart contracts via the detailed analysis of the related publications. However, despite a plethora of research, the application of smart contracts in various industries is different and secreted around to their operational requirements. The actual use of smart contracts is still very limited in practice, especially from the procurement perspective. Nevertheless, the review also found that the widespread research and development of smart contracts in various industries have extended the original functions of smart contracts and made them more comprehensive and efficient to their project needs, such as cross-organizational collaboration and optimization of business processes.

Apart from that, a research framework of smart contracts has been developed for future procurement needs based on this mixed-method review, as shown in Figure 10. On the one hand, most studies have found the benefits of smart contracts, but current research has not gone beyond 
TABLE 7: Potential advantages of smart contracts in the procurement process.

\begin{tabular}{|c|c|}
\hline Potential impact areas & Papers \\
\hline \multicolumn{2}{|l|}{ Supplier management } \\
\hline Supplier selection & \multirow{4}{*}[34,36,49,79,91,95,129,135,166,184]{} \\
\hline Bidding & \\
\hline Relationship management & \\
\hline Contract management & \\
\hline Negotiation & \multirow{3}{*}{$\begin{array}{c}{[11,21,23,32-34,36,40,41,44,45,47,50-52,56,60,61,65,70,73,75,79,84,85,87,88,92-94,98,} \\
100,106,108,112,113,115,118,129,136-138,143,145,149,154,155,160,172,174,175,181,184, \\
186,187]\end{array}$} \\
\hline Documentation sharing & \\
\hline Payment & \\
\hline \multicolumn{2}{|l|}{ Audit } \\
\hline \multicolumn{2}{|l|}{ Logistics management } \\
\hline Time and material conditions & {$[6,24,33,55,88,103,105,114,116,117,119-121,128,129,148,151,156,163,178,180,181,185$} \\
\hline Monitoring & {$[0,24,00,00,00,100,100,114,110,117,119-1121,120,129,140,101,100,100,170,100,101,100$} \\
\hline Logistics information & \\
\hline Goods receipts and storage & \\
\hline
\end{tabular}

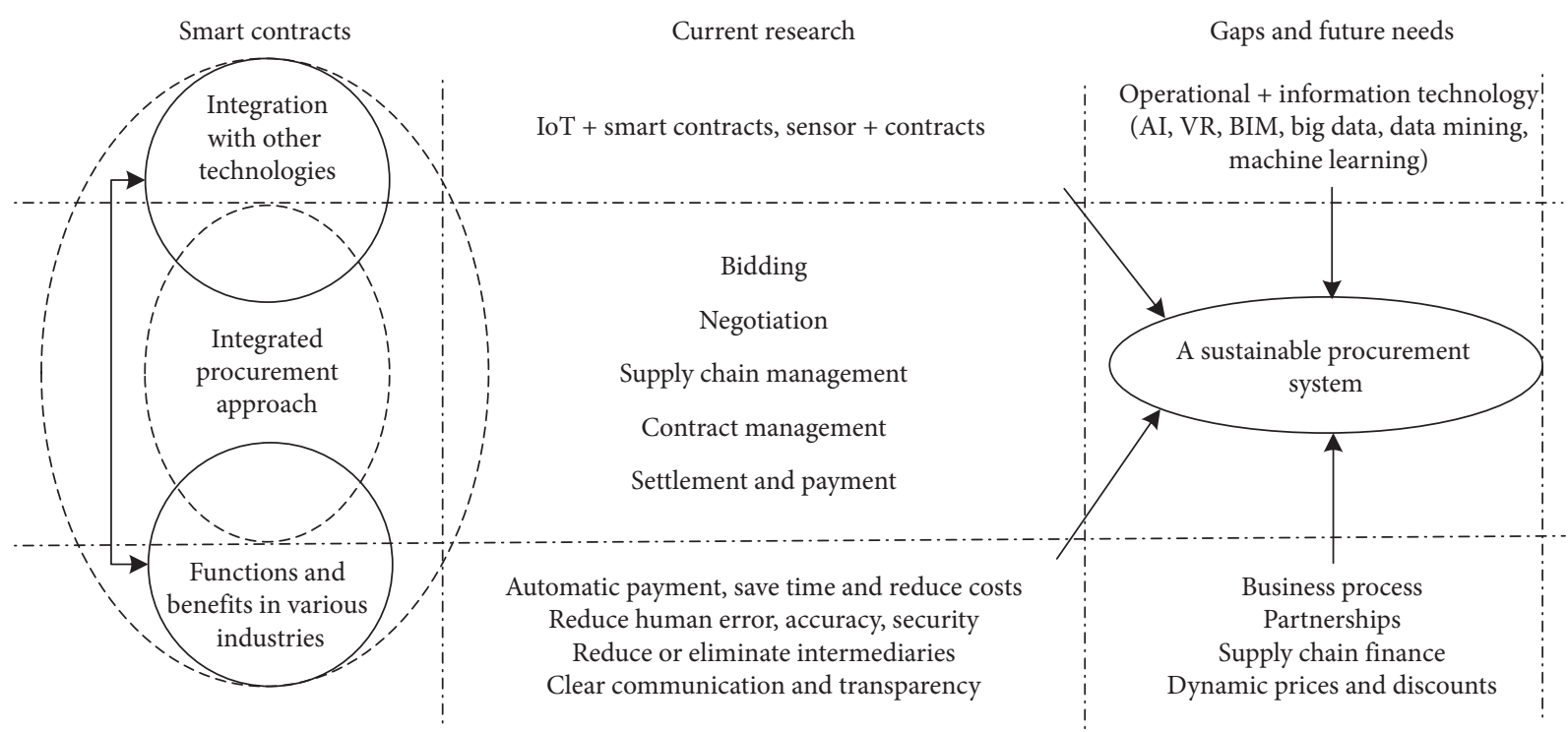

Figure 10: A research framework for smart contracts in future procurement.

conceptual proposals and recommendations and lacks indepth research on smart contracts in terms of procurement. How will smart contracts change the current procurement workflow? How to build an automated financial system through smart contracts? How will smart contracts affect customer relationships? All of these will be significant breakthrough points to achieve sustainable procurement in the future.

On the other hand, the integration of smart contracts with other emerging technologies has received widespread attention from academia and industry by combining smart contracts with IoT devices that can enhance the tracking and control of goods throughout the chain of custody in the entire supply chain [6]. Supply chain management in logistics is very suitable for integrating smart contracts and IoT $[55,83]$. The integration will become a driving force to digitalize the procurement practices or functions in the project [10]. In addition, artificial intelligence, virtual reality, big data, machine learning, etc., will also provide new opportunities for enhancing traditional procurement approaches' performance. For example, big data and data mining can help filter out better partners. Artificial intelligence can automatically trigger replenishment requests, and virtual reality can simplify supplier visits and on-site audits. All these processes can be registered and synchronized under the nodes of smart contracts in improving business operations. The integration of smart contracts with other emerging technologies is the future development trend and research focus, for example, in the construction procurement activities, the integration of smart contract and BIM, in logistics management, the integration of smart contracts with IoT and artificial intelligence, etc.

Future procurement systems will also need to achieve complete predictability of suppliers' information, prices, and costs. In bidding processes, smart contracts can automatically evaluate and recommend the best suppliers based on preset criteria and provide or optimize the best contract prices based on the number of goods and supplier discounts. 
In this situation, the procurement process can fully achieve smart and efficient supplier selection and contract signing and subsequent execution via the self-service procurement operations within smart contracts. For example, the procurement operations will automatically sense material requirements and trigger replenishment requisitions and automatically execute contract terms based on rules and trigger payment. In this regard, it will shorten the approval cycle and eliminate manual errors, and subsequently, it will greatly improve the overall efficiency of business operations. The entire procurement life cycle can be digitalized and improved via smart contracts: the fairness of bidding, the speed of negotiation, the transparency of the supply chain, the convenience of contract management, and the automation of confirmation and payment. Moreover, purchasing based on smart contracts will transform from a purely costdriven transaction to a value-oriented process among project stakeholders. In sum, this framework provides insightful theoretical ideas and practical references of integrated procurement approach based on smart contracts, which is a sustainable procurement system for future procurement needs in business operations across the industries.

\section{Conclusion}

This research has conducted a mixed-method review on the application of smart contracts in various industries to understand their current status, benefits, and potential advantages from the procurement perspective. The research results reveal that the current development of smart contracts is still in its infancy. However, smart contracts have the potential to be widely used across industries, especially in leveraging each industry's strengths or developments in addressing inefficient processes in the current conventional procurement systems. The paper has made contributions to the existing literature of smart contracts in three aspects. First, this article categorizes the application of smart contracts in various industries, summarizes the benefits and functions, and analyzes the current development status. That lays a beneficial foundation for future studies in this field. Secondly, this study uses a systematic and bibliometric review method. The combination of qualitative and quantitative methods provides better methodological reliability in reviewing and analyzing the application of smart contracts in various industries. Third, based on the analyzed data's inductive approach, we establish a research framework for future procurement needs. The proposed integrated approach of the sustainable procurement system provides new insights and opportunities for researchers and procurement practitioners to rethink and reexamine the current procurement system and process.

Nevertheless, certain limitations should be noted in this paper. Firstly, there are still many challenges and technical problems in certain applications of smart contracts, for example, legal uncertainty, technology maturity, and security concerns. Future studies should extend the review to discuss the detailed problems and challenges in applying smart contracts across the perspectives of organization, technology, and environment. Secondly, the search queries may not have been sufficiently comprehensive to capture all publications related to smart contracts application. Future Delphi studies can be conducted by analyzing the experts' knowledge in the field to avoid biases in the analysis of the selected works due to the interdisciplinarity of the research topics. Lastly, as the development of smart contracts is still in its infancy, this study only reviewed research articles. It did not perform a market review to identify the market trends of smart contracts currently used in different industries. In the future, with the increase of the breadth and depth of the application of smart contracts and the increase of practical use cases, we will conduct a more comprehensive study in combination with market development.

\section{Data Availability}

The data used to support the findings of this study are available from the corresponding author upon request.

\section{Conflicts of Interest}

The authors declare that they have no conflicts of interest.

\section{References}

[1] D. Macrinici, C. Cartofeanu, and S. Gao, "Smart contract applications within blockchain technology: a systematic mapping study," Telematics and Informatics, vol. 35, no. 8, pp. 2337-2354, 2018.

[2] S. Rouhani and R. Deters, "Security, performance, and applications of smart contracts: a systematic survey," IEEE Access, vol. 7, pp. 50759-50779, 2019.

[3] T. Feng, X. Yu, Y. Chai, and Y. Liu, "Smart contract model for complex reality transaction," International Journal of Crowd Science, vol. 3, no. 2, pp. 184-197, 2019.

[4] H. Eenmaa-Dimitrieva and M. J. Schmidt-Kessen, "Creating markets in no-trust environments: the law and economics of smart contracts," Computer Law \& Security Review, vol. 35, no. 1, pp. 69-88, 2019.

[5] Z. Zheng, S. Xie, H.-N. Dai et al., "An overview on smart contracts: challenges, advances and platforms," Future Generation Computer Systems, vol. 105, pp. 475-491, 2020.

[6] H. Hasan, E. AlHadhrami, A. AlDhaheri, K. Salah, and R. Jayaraman, "Smart contract-based approach for efficient shipment management," Computers \& Industrial Engineering, vol. 136, pp. 149-159, 2019.

[7] H. Wang, C. Guo, and S. Cheng, "Loc-a new financial loan management system based on smart contracts," Future Generation Computer Systems, vol. 100, pp. 648-655, 2019.

[8] A. Khatoon, "A blockchain-based smart contract system for healthcare management," Electronics, vol. 9, no. 1, p. 94, 2020.

[9] S. Wang, L. Ouyang, Y. Yuan, X. Ni, X. Han, and F.-Y. Wang, "Blockchain-enabled smart contracts: architecture, applications, and future trends," IEEE Transactions on Systems, Man, and Cybernetics: Systems, vol. 49, no. 11, pp. 22662277, 2019.

[10] A. Rejeb, E. Süle, and J. G. Keogh, "Exploring new technologies in procurement," International Journal of Shipping and Transport Logistics, vol. 18, no. 45, pp. 76-86, 2019.

[11] F. Elghaish, S. Abrishami, and M. R. Hosseini, "Integrated project delivery with blockchain: an automated financial 
system," Automation in Construction, vol. 114, Article ID 103182, 2020.

[12] S. Ahmadisheykhsarmast and R. Sonmez, "A smart contract system for security of payment of construction contracts," Automation in Construction, vol. 120, Article ID 103401, 2020.

[13] S. Nakamoto, "Bitcoin: a peer-to-peer electronic cash system," Technical Report, 2008, https://archive.is/rMBtV.

[14] L. W. Cong and Z. He, "Blockchain disruption and smart contracts," The Review of Financial Studies, vol. 32, no. 5, pp. 1754-1797, 2019.

[15] Y. Lu, "The blockchain: state-of-the-art and research challenges," Journal of Industrial Information Integration, vol. 15, pp. 80-90, 2019.

[16] S. Namasudra, G. C. Deka, P. Johri, M. Hosseinpour, and A. H. Gandomi, "The revolution of blockchain: state-ofthe-art and research challenges," Archives of Computational Methods in Engineering, 2020.

[17] S. Perera, S. Nanayakkara, M. N. N. Rodrigo, S. Senaratne, and R. Weinand, "Blockchain technology: is it hype or real in the construction industry?" Journal of Industrial Information Integration, vol. 17, Article ID 100125, 2020.

[18] S. Nick, "The idea of smart contracts," 2017, http://www.fon. hum.uva.nl/rob/Courses/InformationInSpeech/CDROM/ Literature/LOTwinterschool2006/szabo.best.vwh.net/idea.html.

[19] J. Laffont and J. Tirole, A Theory of Incentives in Procurement and Regulation, MIT press, Cambridge, MA, USA, 1993.

[20] N. A. Bakar, K. Peszynski, N. Azizan, V. Pandiyan, and K. Sundram, "Abridgment of traditional procurement and e-procurement: definitions, tools and benefits," Journal of Emerging Economies and Islamic Research, vol. 4, no. 1, pp. 1-18, 2016.

[21] S. E. Chang, Y.-C. Chen, and T.-C. Wu, "Exploring blockchain technology in international trade," Industrial Management \& Data Systems, vol. 119, no. 8, pp. 1712-1733, 2019.

[22] A. Kamali, "Blockchain's potential to combat procurement frauds," International Journal of Software Engineering, Technology, vol. 11, no. 6, pp. 101-107, 2019.

[23] H.-Y. Chong and A. Diamantopoulos, "Integrating advanced technologies to uphold security of payment: data flow diagram," Automation in Construction, vol. 114, Article ID 103158, 2020.

[24] S. Jangir, A. Muzumdar, A. Jaiswal, C. N. Modi, S. Chandel, and C. Vyjayanthi, "A novel framework for pharmaceutical supply chain management using distributed ledger and smart contracts," in Proceedings of the IEEE 10th International Conference on Computing, Communication and Networking Technologies (ICCCNT), pp. 1-7, Kanpur, India, July 2019.

[25] M. Staples and M. Niazi, "Experiences using systematic review guidelines," Journal of Systems and Software, vol. 80, no. 9, pp. 1425-1437, 2007.

[26] D. Denyer and D. Tranfield, "Producing a systematic review," in The Sage Handbook of Organizational Research Methods, D. A. Buchanan and A. Bryman, Eds., pp. 671-689, Sage Publications Ltd, Thousand Oaks, CA, USA, 2009.

[27] A. Bogner, M. Chanson, and A. Meeuw, "A decentralised sharing app running a smart contract on the ethereum blockchain," in Proceedings of the 6th International Conference Internet Things, pp. 177-178, Stuttgart, Germany, November 2016.

[28] K. Christidis and M. Devetsikiotis, "Blockchains and smart contracts for the internet of things," IEEE Access, vol. 4, pp. 2292-2303, 2016.
[29] T. Nugent, D. Upton, and M. Cimpoesu, "Improving data transparency in clinical trials using blockchain smart contracts," F1000Research, vol. 5, 2016.

[30] A. Yasin and L. Liu, "An online identity and smart contract management system," in Proceedings of the IEEE 40th Annual Computer Software and Applications Conference (COMPSAC), vol. 2, pp. 192-198, Atlanta, GA, USA, June 2016.

[31] P. McCorry, S. F. Shahandashti, and F. Hao, "A smart contract for boardroom voting with maximum voter privacy," in Proceedings of the International Conference on Financial Cryptography and Data Security, pp. 357-375, Springer, Sliema, Malta, April 2017.

[32] L. Thomas, C. Long, P. Burnap, J. Wu, and N. Jenkins, "Automation of the supplier role in the GB power system using blockchain-based smart contracts," CIRED-Open Access Proceedings Journal, vol. 2017, no. 1, pp. 2619-2623, 2017.

[33] R. Hans, H. Zuber, A. Rizk, and R. Steinmetz, "Blockchain and smart contracts: disruptive technologies for the insurance market," in Proceedings of the 23th Am. Conference Info. Syst. (AMCIS), pp. 1-10, Boston, MA, USA, August 2017.

[34] I. Kounelis, G. Steri, R. Giuliani, D. Geneiatakis, R. Neisse, and I. Nai-Fovino, "Fostering consumers' energy market through smart contracts," in Proceedings of the International Conference Energy Sustainability Small Developing Economies (ES2DE), pp. 1-6, Funchal, Portugal, July 2017.

[35] H. M. Gazali, R. Hassan, R. M. Nor, and H. M. Rahman, "Reinventing PTPTN study loan with blockchain and smart contracts," in Proceedings of the 8th International Conference on Information Technology (ICIT), pp. 751-754, Amman, Jordan, May 2017.

[36] A. Hahn, R. Singh, C.-C. Liu, and S. Chen, "Smart contractbased campus demonstration of decentralized transactive energy auctions," in Proceedings of the IEEE Power Energy Society Innovative Smart Grid Technologies Conference (ISGT), pp. 1-5, Washington, DC, USA, April 2017.

[37] N. Álvarez-Díaz, J. Herrera-Joancomartí, and P. CaballeroGil, "Smart contracts based on blockchain for logistics management," in Proceedings of the 1st International Conference on Internet of Things and Machine Learning, p. 73, Liverpool, UK, October 2017.

[38] M. Saravanan, S. Behera, and V. Iyer, "Smart contracts in mobile telecom networks," in Proceedings of the 23rd Annual International Conference in Advanced Computing and Communications (ADCOM), pp. 27-33, Bangalore, India, September 2017.

[39] P. Sreehari, M. Nandakishore, G. Krishna, J. Jacob, and V. Shibu, "Smart will converting the legal testament into a smart contract," in Proceedings of the IEEE Networks \& Advances in Computational Technologies NETACT, pp. 203-207, Thiruvanthapuram, India, July 2017.

[40] V. Shermin, "Disrupting governance with blockchains and smart contracts," Strategic Change, vol. 26, no. 5, pp. 499-509, 2017.

[41] J. Mason, "Intelligent contracts and the construction industry," Journal of Legal Affairs and Dispute Resolution in Engineering and Construction, vol. 9, no. 3, Article ID 04517012, 2017.

[42] S. Kirkman, "A data movement policy framework for improving trust in the cloud using smart contracts and blockchains," in Proceedings of the IEEE International Conference on Cloud Engineering (IC2E), pp. 270-273, Orlando, FL, USA, April 2018. 
[43] S. Wang, X. Ni, Y. Yuan, F.-Y. Wang, X. Wang, and L. Ouyang, "A preliminary research of prediction markets based on blockchain powered smart contracts," in Proceedings of the IEEE International Conference Blockchain (Blockchain), pp. 1287-1293, Halifax, Canada, July 2018.

[44] Y. Hou, Y. Chen, Y. Jiao et al., "A resolution of sharing private charging piles based on smart contract," in Proceedings of the 13th International Conference on Natural Computation, Fuzzy Systems and Knowledge Discovery (ICNC-FSKD), pp. 3004-3008, Guilin, China, July 2017.

[45] K.-H. Yeh, C. Su, J.-L. Hou, W. Chiu, and C.-M. Chen, “A robust mobile payment scheme with smart contract-based transaction repository," IEEE Access, vol. 6, pp. 5939459404, 2018.

[46] H. Desai, K. Liu, M. Kantarcioglu, and L. Kagal, "Adjudicating violations in data sharing agreements using smart contracts," in Proceedings of the IEEE International Conference Internet Things (iThings) IEEE Green Computing and Communications (GreenCom) IEEE Cyber, Physical and Social Computing (CPSCom) IEEE Smart Data (SmartData), pp. 1553-1560, Halifax, Nova Scotia, Canada, July 2018.

[47] O. Mahmoud, H. Kopp, A. T. Abdelhamid, and F. Kargl, "Applications of smart-contracts: anonymous decentralized insurances with IoT sensors," in Proceedings of the IEEE International Conference on Internet of Things (iThings) and IEEE Green Computing and Communications (GreenCom) IEEE Cyber, Physical and Social Computing (CPSCom) IEEE Smart Data (SmartData), pp. 1507-1512, Halifax, Nova Scotia, Canada, July 2018.

[48] A. M. Rozario and M. A. Vasarhelyi, "Auditing with smart contracts," The International Journal of Digital Accounting Research, vol. 18, pp. 1-27, 2018.

[49] Y.-H. Chen, S.-H. Chen, and I.-C. Lin, "Blockchain based smart contract for bidding system," in Proceedings of the IEEE International Conference on Applied System Invention (ICASI), pp. 208-211, Chiba, Japan, April 2018.

[50] S. Zhao and D. O'Mahony, "BMCProtector: a blockchain and smart contract based application for music copyright protection," in Proceedings of the International Conference on Blockchain Technology and Application, pp. 1-5, Xi'an, China, December 2018.

[51] Y. Zhong, B. Duan, Y. Yan, X. Qu, and Q. Yin, "Enhancing peak load shifting effect by using smart contract of electric vehicle charging," in Proceedings of the 11th IET International Conference on Advances in Power System Control, Operation and Management (APSCOM), pp. 5-9, Hong Kong, China, November 2018.

[52] N. Gupta and P. Bedi, "E-waste management using blockchain based smart contracts," in Proceedings of the International Conference on Advances in Computing, Communications and Informatics (ICACCI), pp. 915-921, Bangalore, India, September 2018.

[53] K. N. Griggs, O. Ossipova, C. P. Kohlios, A. N. Baccarini, E. A. Howson, and T. Hayajneh, "Healthcare blockchain system using smart contracts for secure automated remote patient monitoring," Journal of Medical Systems, vol. 42, no. 7, pp. 130-138, 2018.

[54] Y. Zhou, M. Han, L. Liu, Y. Wang, Y. Liang, and L. Tian, "Improving iot services in smart-home using blockchain smart contract," in Proceedings of the IEEE International Conference Internet Things (iThings) IEEE Green Computing and Communications (GreenCom) IEEE Cyber, Physical and Social Computing (CPSCom) IEEE Smart Data (SmartData), pp. 81-87, Halifax, Nova Scotia, Canada, July 2018.
[55] S. S. Arumugam, V. Umashankar, N. C. Narendra et al., "IOT enabled smart logistics using smart contracts," in Proceedings of the 8th International Conference on Logistics, Informatics and Service Sciences (LISS), pp. 1-6, Toronto, Ontario, Canada, August 2018.

[56] M. Stefanović, S. Ristić, D. Stefanović, M. Bojkić, and D. Pržulj, "Possible applications of smart contracts in land administration," in Proceedings of the 26th Telecommunications Forum (TELFOR), pp. 420-425, Belgrade, Serbia, November 2018.

[57] M. N. Islam and S. Kundu, "Poster abstract: preserving IoT privacy in sharing economy via smart contract," in Proceedings of the International Conference on Internet-of-Things Design and Implementation (IoTDI), pp. 296-297, Orlando, FL, USA, April 2018.

[58] H. R. Hasan and K. Salah, "Proof of delivery of digital assets using blockchain and smart contracts," IEEE Access, vol. 6, pp. 65439-65448, 2018.

[59] J. P. Cruz, Y. Kaji, and N. Yanai, "RBAC-SC: role-based access control using smart contract," IEEE Access, vol. 6, pp. 12240-12251, 2018.

[60] S. R. Niya, F. Shüpfer, T. Bocek, and B. Stiller, "Setting up flexible and light weight trading with enhanced user privacy using smart contracts," in Proceedings of the IEEE/IFIP Network Operations and Management Symposium (NOMS), pp. 1-2, Seoul, Korea, April 2018.

[61] A. Fedosov, A. Bexheti, E. Ermolaev, and M. Langheinrich, "Sharing physical objects using smart contracts," in Proceedings of the 20th International Conference on HumanComputer Interaction with Mobile Devices and Services Adjunct, pp. 346-352, Barcelona, Spain, September 2018.

[62] A.-T. Pãnescu and V. Manta, "Smart contracts for research data rights management over the ethereum blockchain network," Science \& Technology Libraries, vol. 37, no. 3, pp. 235-245, 2018.

[63] N. Fotiou and G. C. Polyzos, "Smart contracts for the internet of things: opportunities and challenges," in Proceedings of the European Conference Networks Communications (EuCNC), pp. 256-260, Ljubljana, Slovenia, June 2018.

[64] R. C. de Souza, E. M. Luciano, and G. C. Wiedenhöft, "The uses of the blockchain smart sontracts to reduce the levels of corruption: some preliminary thoughts," in Proceedings of the 19th Annual International Conference on Digital Government Research, Governance Data Age, pp. 1-110, New York, NY, USA, May 2018.

[65] A. Norta, C. Fernandez, and S. Hickmott, "Commercial property tokenizing with smart contracts," in Proceedings of the International Joint Conference Neural Networks (IJCNN), pp. 1-8, Rio de Janeiro, Brazil, July 2018.

[66] Y. Gu, J. Chen, and X. Wu, "An implement of smart contract based decentralized online crowdsourcing mechanism," in Proceedings of the 2nd International Conference on Computer Science and Artificial Intelligence, pp. 195-199, Louisville, KY, USA, December 2018.

[67] R. Xu, Y. Chen, E. Blasch, and G. Chen, "Blendcac: a smart contract enabled decentralized capability-based access control mechanism for the IoT," Computers, vol. 7, no. 3, p. 39, 2018.

[68] J.-C. Cheng, N.-Y. Lee, C. Chi, and Y.-H. Chen, "Blockchain and smart contract for digital certificate," in Proceedings of the IEEE International Conference on Applied System Innovation (ICASI), pp. 1046-1051, Chiba, Japan, April 2018.

[69] V. Gatteschi, F. Lamberti, C. Demartini, C. Pranteda, and V. Santamaría, "Blockchain and smart contracts for 
insurance: is the technology mature enough?" Future Internet, vol. 10, no. 2, p. 20, 2018.

[70] M. Król, S. Reñé, O. Ascigil, and I. Psaras, "ChainSoft: collaborative software development using smart contracts," in Proceedings of the 1st Workshop Cryptocurrencies and Blockchains for Distributed Systems (CryBlock), pp. 1-6, New York, NY, USA, June 2018.

[71] B. Y. Kim, S. S. Choi, and J. W. Jang, "Data managing and service exchanging on IoT service platform based on blockchain with smart contract and spatial data processing," in Proceedings of the International Conference on Information Technology \& Systems, pp. 59-63, Jeju, Korea, April 2018.

[72] P. Bedi, P. Gole, S. Dhiman, and N. Gupta, "Smart contract based central sector scheme of scholarship for college and university students," Procedia Computer Science, vol. 171, pp. 790-799, 2020.

[73] F. Lamberti, V. Gatteschi, C. Demartini, M. Pelissier, A. Gomez, and V. Santamaria, "Blockchains can work for car insurance: using smart contracts and sensors to provide ondemand coverage," IEEE Consumer Electronics Magazine, vol. 7, no. 4, pp. 72-81, 2018.

[74] A. S. Omar and O. Basir, "Identity management in IoT networks using blockchain and smart contracts," in Proceedings of the IEEE International Conference on Internet of Things (iThings 2018) and IEEE Green Computing and Communications (GreenCom 2018) and IEEE Cyber, Physical and Social Computing (CPSCom 2018) and IEEE Smart Data (SmartData 2018), pp. 994-1000, Halifax, Nova Scotia, Canada, July 2018.

[75] S. Nayak, N. C. Narendra, A. Shukla, and J. Kempf, "Saranyu: using smart contracts and blockchain for cloud tenant management," in Proceedings of the IEEE 11th International Conference on Utility and Cloud Computing (CLOUD), pp. 857-861, Zurich, Switzerland, December 2018.

[76] S. P. Novikov, O. D. Kazakov, N. A. Kulagina, and N. Y. Azarenko, "Blockchain and smart contracts in a decentralized health infrastructure," in Proceedings of the IEEE International Conference Quality Management, Transport and Information Security, Information Technologies (IT\&QMßIS), pp. 697-703, Saint Petersburg, Russia, September 2018.

[77] R. B. Uriarte, R. De Nicola, and K. Kritikos, "Towards distributed SLA management with smart contracts and blockchain," in Proceedings of the IEEE International Conference on Cloud Computing Technology and Science (CloudCom), pp. 266-271, Nicosia, Cyprus, December 2018.

[78] H. Zhou, C. de Laat, and Z. Zhao, "Trustworthy cloud service level agreement enforcement with blockchain based smart contract," in Proceedings of the IEEE International Conference on Cloud Computing Technology and Science (CloudCom), pp. 255-260, Nicosia, Cyprus, December 2018.

[79] S. Yu, S. Yang, Y. Li, and J. Geng, "Distributed energy transaction mechanism design based on smart contract," in Proceedings of the China International Conference on Electricity Distribution (CICED), pp. 2790-2793, Tianjin, China, September 2018

[80] G. Papadodimas, G. Palaiokrasas, A. Litke, and T. Varvarigou, "Implementation of smart contracts for blockchain based IoT applications," in Proceedings of the 9th International Conference on the Network of the Future (NOF), pp. 60-67, Poznan, Poland, November 2018.

[81] J. Lyu, Z. L. Jiang, X. Wang, Z. Nong, M. H. Au, and J. Fang, "A secure decentralized trustless E-voting system based on smart contract," in Proceedings of the 18th IEEE International
Conference On Trust, Security And Privacy In Computing And Communications/13th IEEE International Conference On Big Data Science And Engineering (TrustCom/BigDataSE), pp. 570-577, Rotorua, New Zealand, August 2019.

[82] H. L. Pham, T. H. Tran, and Y. Nakashima, "A secure remote healthcare system for hospital using blockchain smart contract," in Proceedings of the IEEE Globecom Workshops (GC Wkshps), pp. 1-6, Abu Dhabi, UAE, December 2018.

[83] L. Augusto, R. Costa, J. Ferreira, and R. Jardim-Gonçalves, "An application of Ethereum smart contracts and IoT to logistics," in Proceedings of the International Young Engineers Forum on Electrical and Computer Engineering (YEF-ECE), pp. 1-7, Costa da Caparica, Portugal, May 2019.

[84] V. Aleksieva, H. Valchanov, and A. Huliyan, "Application of smart contracts based on ethereum blockchain for the purpose of insurance services," in Proceedings of the International Conference on Biomedical Innovations and Applications (BIA), pp. 1-4, Varna, Bulgaria, November 2019.

[85] N. T. T. Le, Q. Nghiep, N. Ngoc et al., "Assuring nonfraudulent transactions in cash on delivery by introducing double smart contracts," International Journal of Advanced Computer Science and Applications, vol. 10, no. 5, pp. 677684, 2019.

[86] J. Li, Z. Zhang, and M. Li, "BanFEL: a blockchain based smart contract for fair and efficient lottery scheme," in Proceedings of the IEEE Conference on Dependable Secure Comput. (DSC), pp. 1-8, Hangzhou, China, November 2019.

[87] B. Pittl, S. Starflinger, W. Mach, and E. Schikuta, "Bazaarcontract: a smart contract for binding multi-round bilateral negotiations on cloud markets," in Proceedings of the 7 th International Conference Future Internet Things Cloud (FiCloud), pp. 147-154, Istanbul, Turkey, August 2019.

[88] R. Philipp, G. Prause, and L. Gerlitz, "Blockchain and smart contracts for entrepreneurial collaboration in maritime supply chains," Transport and Telecommunication Journal, vol. 20, no. 4, pp. 365-378, 2019.

[89] L. M. Palma, M. A. Vigil, F. L. Pereira, and J. E. Martina, "Blockchain and smart contracts for higher education registry in Brazil," International Journal of Network Management, vol. 29, no. 3, Article ID e2061, 2019.

[90] A. Kiran, S. Dharanikota, and A. Basava, "Blockchain based data access control using smart contracts," in Proceedings of the IEEE Region 10 Conference (TENCON), pp. 2335-2339, Kerala, India, October 2019.

[91] P. Manimaran and R. Dhanalakshmi, "Blockchain-based smart contract for e-bidding system," in Proceedings of the 2nd International Conference on Intelligent Communication and Computational Techniques (ICCT), pp. 55-59, Jaipur, India, September 2019.

[92] S. J. Pee, E. S. Kang, J. G. Song, and J. W. Jang, "Blockchain based smart energy trading platform using smart contract," in Proceedings of the International Conference on Artificial Intelligence in Information and Communication (ICAIIC), pp. 322-325, Okinawa, Japan, February 2019.

[93] Q. Wang, R. Y. K. Lau, and X. Mao, "Blockchain-enabled smart contracts for enhancing distributor-to-consumer transactions," IEEE Consumer Electronics Magazine, vol. 8, no. 6, pp. 22-28, 2019.

[94] H. Luo, M. Das, J. Wang, and J. Cheng, "Construction payment automation through smart contract-based blockchain framework," in Proceedings of the 36th International Symposium on Automation and Robotics in Construction (ISARC), vol. 36, pp. 1254-1260, Banff Alberta, Canada, May 2019. 
[95] S. Wu, Y. Chen, Q. Wang, M. Li, C. Wang, and X. Luo, "CReam: a smart contract enabled collusion-resistant e-auction," IEEE Transactions on Information Forensics and Security, vol. 14, no. 7, pp. 1687-1701, 2018.

[96] V. Singla, I. K. Malav, J. Kaur, and S. Kalra, "Develop leave application using blockchain smart contract," in Proceedings of the 11th International Conference on COMmunication Systems and NETworkS (COMSNETS), pp. 547-549, Bangalore, India, January 2019.

[97] V. C. Nguyen, P. Hoai-Luan, T. Thi-Hong, H. T. Huynh, and Y. Nakashima, "Digitizing invoice and managing VAT payment using blockchain smart contract," in Proceedings of the IEEE International Conference on Blockchain and Cryptocurrency (ICBC), pp. 74-77, Seoul, Korea, May 2019.

[98] H. Liu, Y. Zhang, S. Zheng, and Y. Li, "Electric vehicle power trading mechanism based on blockchain and smart contract in V2G network," IEEE Access, vol. 7, pp. 160546-160558, 2019.

[99] Y. Liu, G. Sun, and S. Schuckers, "Enabling secure and privacy preserving identity management via smart contract," in Proceedings of the IEEE Conference on Communications and Network Security (CNS), pp. 1-8, Washington, DC, USA, June 2019.

[100] U. Asfia, V. Kamuni, A. Sheikh, S. Wagh, and D. Patel, "Energy trading of electric vehicles using blockchain and smart contracts," in Proceedings of the 18th European Control Conference (ECC), pp. 3958-3963, Naples, Italy, June 2019.

[101] H.-A. Pham, T.-K. Le, and T.-V. Le, "Enhanced security of IoT data sharing management by smart contracts and blockchain," in Proceedings of the 19th International Symposium on Communications and Information Technologies (ISCIT), pp. 398-403, Ho Chi Minh City, Vietnam, September 2019.

[102] R. Neiheiser, G. Inácio, L. Rech, and J. Fraga, "HRM smart contracts on the blockchain," in Proceedings of the IEEE Symposium on Computers and Communications (ISCC), pp. 1-6, Barcelona, Spain, June 2019.

[103] R. dos Santos, N. Torrisi, E. Yamada, and R. Pantoni, "IGR token-raw material and ingredient certification of recipe based foods using smart contracts," Informatics, vol. 6, no. 1, p. 11, 2019.

[104] M. Malan and A. Steyn, "Implementing smart contracts in the syndicated loan market: an issue of adoption," IT Professional, vol. 21, no. 5, pp. 39-47, 2019.

[105] H. Baharmand and T. Comes, "Leveraging partnerships with logistics service providers in humanitarian supply chains by blockchain-based smart contracts," IFAC-PapersOnLine, vol. 52, no. 13, pp. 12-17, 2019.

[106] T. Q. Nguyen, A. K. Das, and L. T. Tran, "NEO smart contract for drought-based insurance," in Proceedings of the IEEE Canadian Conference of Electrical and Computer Engineering (CCECE), pp. 1-4, Edmonton, AB, Canada, May 2019.

[107] Q. Yang, X. Zeng, Y. Zhang, and W. Hu, "New loan system based on smart contract," in Proceedings of the ACM International Symposium on Blockchain and Secure Critical Infrastructure, pp. 121-126, Auckland, New Zealand, July 2019.

[108] B. Duan, K. Xin, and Y. Zhong, "Optimal dispatching of electric vehicles based on smart contract and internet of things," IEEE Access, vol. 8, pp. 9630-9639, 2019.

[109] A. Giordanengo, "Possible usages of smart contracts (blockchain) in healthcare and why no one is using them," Studies in Health Technology and Informatics, vol. 264, pp. 596-600, 2019.
[110] E. Zaghloul, T. Li, and J. Ren, "Security and privacy of electronic health records: decentralized and hierarchical data sharing using smart contracts," in Proceedings of the International Conference on Computing, Networking and Communications(ICNC), pp. 375-379, Honolulu, HI, USA, February 2019.

[111] Y. Voutos, G. Drakopoulos, and P. Mylonas, "Smart agriculture: an open field for smart contracts," in Proceedings of the 4th South-East Europe Design Automation, Computer Engineering, Computer Networks and Social Media Conference (SEEDA-CECNSM), pp. 1-6, Piraeus, Greece, September 2019.

[112] H. Zhang, E. Deng, H. Zhu, and Z. Cao, "Smart contract for secure billing in ride-hailing service via blockchain," Peerto-Peer Networking and Applications, vol. 12, no. 5, pp. 1346-1357, 2019.

[113] L. Bader, J. C. Bürger, R. Matzutt, and K. Wehrle, "Smart contract-based car insurance policies," in Proceedings of the IEEE Globecom Workshops (GC Wkshps), pp. 1-7, Abu Dhabi, UAE, December 2018.

[114] F. Qu, H. Haddad, and H. Shahriar, "Smart contract-based secured business-to-consumer supply chain systems," in Proceedings of the IEEE International Conference on Blockchain (Blockchain), pp. 580-585, Atlanta, GA, USA, July 2019.

[115] Y. Hanada, L. Hsiao, and P. Levis, "Smart contracts for machine-to-machine communication: possibilities and limitations," in Proceedings of the IEEE International Conference on Internet of Things and Intelligence System (IOTAIS), pp. 130-136, Bali, Indonesia, November 2018.

[116] G. Prause and I. Boevsky, "Smart contracts for smart rural supply chains," Bulgarian Journal of Agricultural Science, vol. 25, no. 3, pp. 454-463, 2019.

[117] G. Prause, "Smart contracts for smart supply chains," IFACPapersOnLine, vol. 52, no. 13, pp. 2501-2506, 2019.

[118] A. Asgaonkar and B. Krishnamachari, "Solving the buyer and seller's dilemma: a dual-deposit escrow smart contract for provably cheat-proof delivery and payment for a digital good without a trusted mediator," in Proceedings of the IEEE International Conference Blockchain Cryptocurrency (ICBC), pp. 262-267, Seoul, Korea, May 2019.

[119] S. E. Chang, Y.-C. Chen, and M.-F. Lu, "Supply chain reengineering using blockchain technology: a case of smart contract based tracking process," Technological Forecasting and Social Change, vol. 144, pp. 1-11, 2019.

[120] R. C. Koirala, K. Dahal, and S. Matalonga, "Supply chain using smart contract: a blockchain enabled model with traceability and ownership management," in Proceedings of the 9th International Conference On Cloud Computing, Data Science and Engineering (Confluence), pp. 538-544, Noida, India, January 2019.

[121] S. Terzi, A. Zacharaki, A. Nizamis et al., "Transforming the supply-chain management and industry logistics with blockchain smart contracts," in Proceedings of the 23rd PanHellenic Conference on Informatics, pp. 9-14, Nicosia, Cyprus, November 2019.

[122] B. K. Mohanta, D. Jena, and U. Satapathy, "Trust management in IoT enable healthcare system using Ethereum based smart contract," International Journal of Scientific and Technology Research, vol. 8, no. 9, pp. 758-763, 2019.

[123] B. Zhao, L. Fang, H. Zhang et al., "Y-DWMS: a digital watermark management system based on smart contracts," Sensors, vol. 19, no. 14, p. 3091, 2019.

[124] S. Lin, J. Li, X. Jia, and J. Gong, "Research on confirming the rights of government data resources based on smart 
contract," in Proceedings of the IEEE 4th Advanced Information Technology, Electronic and Automation Control Conference (IAEAC), vol. 1, pp. 1675-1679, Chengdu, China, December 2019.

[125] J. Gong, S. Lin, and J. Li, "Research on personal health data provenance and right confirmation with smart contract," in Proceedings of the IEEE 4th Advanced Information Technology, Electronic and Automation Control Conference (IAEAC), vol. 1, pp. 1211-1216, Chengdu, China, December 2019.

[126] V. S. Vidhyalakshmi, A. Geetha, and S. Sobitha Ahila, "Real estate management using smart contracts," International Journal of Advanced Science and Technology, vol. 28, no. 13, pp. 616-621, 2019.

[127] H. R. Hasan and K. Salah, "Combating deepfake videos using blockchain and smart contracts," IEEE Access, vol. 7, pp. 41596-41606, 2019.

[128] S. Wang, D. Li, Y. Zhang, and J. Chen, "Smart contract-based product traceability system in the supply chain scenario," IEEE Access, vol. 7, pp. 115122-115133, 2019.

[129] A. Jaiswal, S. Chandel, A. Muzumdar, G. Madhu, C. Modi, and C. Vyjayanthi, "A conceptual framework for trustworthy and incentivized trading of food grains using distributed ledger and smart contracts," in Proceedings of the IEEE 16th India Council International Conference (INDICON), pp. 1-4, Rajkot, India, December 2019.

[130] H. You, H. Hua, and J. Cao, "A smart contract-based energy trading strategy in energy internet," in Proceedings of the IEEE International Conference Energy Internet (ICEI), pp. 478-483, Nanjing, China, May 2019.

[131] W.-K. Yang, J.-S. Chen, and Y.-S. Chen, "An electronic medical record management system based on smart contracts," in Proceedings of the 12th International Conference on Ubi-Media Computing (Ubi-Media), pp. 220-223, Bali, Indonesia, August 2019.

[132] D. A. Batista and T. Weingaertner, "ArchContract: using smart contracts for disposition," in Proceedings of the IEEE International Conference Big Data (Big Data), pp. 30603065, Los Angeles, CA, USA, December 2019.

[133] A. Sheth and H. Subramanian, "Blockchain and contract theory: modeling smart contracts using insurance markets," Managerial Finance, vol. 46, no. 6, pp. 803-814, 2019.

[134] D. R. Putra, B. Anggorojati, and A. P. P. Hartono, "Blockchain and smart-contract for scalable access control in internet of things," in Proceedings of the International Conference on ICT for Smart Society (ICISS), pp. 1-5, Bandung, Indonesia, November 2019.

[135] B. L. V. V. Kumar and K. Raja Kumar, "Blockchain based smart contract for sealed-bid auction," International Journal of Engineering and Advanced Technology, vol. 8, no. 6, pp. 628-631, 2019.

[136] N. Zhao and H. Wu, "Blockchain combined with smart contract to keep safety energy trading for autonomous vehicles," in Proceedings of the IEEE 89th Vehicular Technology Conference (VTC2019-Spring), pp. 1-5, Kuala Lumpur, Malaysia, April 2019.

[137] M. Jintapitak, M. A. Ansari, C. Kamyod, W. Singkhamfu, N. S. Kamthe, and P. Temdee, "Blockchain eco-system for Thai insect industry: a smart contract conceptual framework," in Proceedings of the 22nd International Symposium on Wireless Personal Multimedia Communications (WPMC), pp. 1-4, Lisbon, Portugal, November 2019.

[138] X. Wang, W. Yang, S. Noor, C. Chen, M. Guo, and K. H. van Dam, "Blockchain-based smart contract for energy demand management," Energy Procedia, vol. 158, pp. 2719-2724, 2019.

[139] P. K. Poptawski and K. Szczypiorski, "Blockchain-based smart contracts for sustainable power investments," in Proceedings of the Second World Conference Smart Trends in Systems, Security and Sustainability (WorldS4), pp. 1-8, London, UK, October 2018.

[140] A. Bracciali, I. Chatzigiannakis, A. Vitaletti, and M. Zecchini, "Citizens vote to act: smart contracts for the management of water resources in smart cities," in Proceedings of the First International Conference Societal Automation (SA), pp. 1-8, Krakow, Poland, September 2019.

[141] J. Mihelj, Y. Zhang, A. Kos, and U. Sedlar, "Crowdsourced traffic event detection and source reputation assessment using smart contracts," Sensors, vol. 19, no. 15, p. 3267, 2019.

[142] B. Ekici, A. Tarhan, and A. Ozsoy, "Data cleaning for process mining with smart contract," in Proceedings of the 4th International Conference on Computer Science and Engineering (UBMK), pp. 1-6, Samsun, Turkey, September 2019.

[143] M. Vinayak, S. dos Santos, R. K. Thulasiram, P. Thulasiraman, and S. S. Appadoo, "Design and implementation of financial smart contract services on blockchain," in Proceedings of the IEEE 10th Annual IEEE Information Technology, Electronics and Mobile Communication Conference (IEMCON), pp. 1023-1030, Vancouver, BC, Canada, October 2019.

[144] T. Li and Y. Liu, "Design and implementation of secondhand goods renting system based on Ethereum smart contract," in Proceedings of the 4th International Conference on Intelligent Information Processing, pp. 346-351, Beijing, China, November 2019.

[145] Y. Li, W. Yang, P. He, C. Chen, and X. Wang, "Design and management of a distributed hybrid energy system through smart contract and blockchain," Applied Energy, vol. 248, pp. 390-405, 2019.

[146] R. Poorni, M. Lakshmanan, and S. Bhuvaneswari, "DIGICERT: a secured digital certificate application using blockchain through smart contracts," in Proceedings of the International Conference on Communication and Electronics Systems (ICCES), pp. 215-219, Coimbatore, India, July 2019.

[147] P. Qian, Z. Liu, X. Wang, J. Chen, B. Wang, and R. Zimmermann, "Digital resource Rights confirmation and infringement tracking based on smart contracts," in Proceedings of the IEEE 6th International Conference on Cloud Computing and Intelligence Systems (CCIS), pp. 62-67, Singapore, December 2019.

[148] P. De Giovanni, "Digital supply chain through dynamic inventory and smart contracts," Mathematics, vol. 7, no. 12, p. 1235, 2019.

[149] C. Chen, T. Xiao, T. Qiu, N. Lv, and Q. Pei, "Smart-contractbased economical platooning in blockchain-enabled urban internet of vehicles," IEEE Transactions on Industrial Informatics, vol. 16, no. 6, pp. 4122-4133, 2019.

[150] A. Bagozi, D. Bianchini, V. De Antonellis, M. Garda, and M. Melchiori, "Exploiting blockchain and smart contracts for data exploration as a service," in Proceedings of the 21st International Conference on Information Integration and Web-based Applications \& Services, pp. 393-402, Munich, Germany, December 2019.

[151] H. Moudoud, S. Cherkaoui, and L. Khoukhi, "An IoT blockchain architecture using oracles and smart contracts: the use-case of a food supply chain," in Proceedings of the 2019 IEEE 30th Annual International Symposium on 
Personal, Indoor and Mobile Radio Communications (PIMRC), pp. 1-6, Istanbul, Turkey, September 2019.

[152] I. Kovalenko, Y. Davydenko, A. Shved, and A. Boiko, "Efficient funds allocation system based on fuzzy logic and smart contracts," in Proceedings of the IEEE 14th International Conference on Computer Sciences and Information Technologies (CSIT), pp. 214-217, Lviv, Ukraine, September 2019.

[153] J. Dai, N. He, and H. Yu, "Utilizing blockchain and smart contracts to enable audit 4.0: from the perspective of accountability audit of air pollution control in China," Journal of Emerging Technologies in Accounting, vol. 16, no. 2, pp. 23-41, 2019.

[154] K. P. Lin, Y. W. Chang, Z. H. Wei, C. Y. Shen, and M. Y. Chang, "A smart contract-based mobile ticketing system with multi-signature and blockchain," in Proceedings of the IEEE 8th Global Conference on Consumer Electronics (GCCE), pp. 231-232, Osaka, Japan, October 2019.

[155] I. G. B. B. Nugraha, Y. Bandung, and A. Zaky, "Official document management for government service in Indonesia using smart contract," in Proceedings of the IEEE International Smart Cities Conference (ISC2), pp. 390-395, Casablanca, Morocco, October 2019.

[156] J. M. Montes, C. E. Ramirez, M. C. Gutierrez, and V. M. Larios, "Smart contracts for supply chain applicable to smart cities daily operations," in Proceedings of the IEEE International Smart Cities Conference (ISC2), pp. 565-570, Casablanca, Morocco, October 2019.

[157] I. A. Omar, R. Jayaraman, K. Salah, and M. C. E. Simsekler, "Exploiting ethereum smart contracts for clinical trial management," in Proceedings of the IEEE/ACS 16th International Conference on Computer Systems and Applications (AICCSA), pp. 1-6, Abu Dhabi, UAE, November 2019.

[158] S. Avizheh, M. Nabi, R. Safavi-Naini, and K. M. Venkateswarlu, "Verifiable computation using smart contracts," in Proceedings of the ACM SIGSAC Conference Cloud Computing Security Workshop (CCSW), pp. 17-28, London, UK, November 2019.

[159] T. Le and M. W. Mutka, "PPCA: privacy-preserving conditional actions for IoT environments using smart contracts," in Proceedings of the 16th EAI International Conference on Mobile and Ubiquitous Systems: Computing, Networking and Services, pp. 172-179, Houston, TX, USA, November 2019.

[160] P. Kumar, G. A. Dhanush, D. Srivatsa, S. N. Aakash, and S. Sahisnu, "An efficient and novel buyer and seller's distributed ledger based protocol using smart contracts," in Proceedings of the International Conference on Distributed Computing and Internet Technology, pp. 349-363, Bhubaneswar, India, January 2020.

[161] H. Wang, H. Qin, M. Zhao, X. Wei, H. Shen, and W. Susilo, "Blockchain-based fair payment smart contract for public cloud storage auditing," Information Sciences, vol. 519, pp. 348-362, 2020.

[162] M. R. Dorsala, V. N. Sastry, and S. Chapram, "Fair payments for verifiable cloud services using smart contracts," Computers \& Security, vol. 90, Article ID 101712, 2020.

[163] B. Yu, P. Zhan, M. Lei, F. Zhou, and P. Wang, "Food quality monitoring system based on smart contracts and evaluation models," IEEE Access, vol. 8, pp. 12479-12490, 2020.

[164] R. Neiheiser, G. Inácio, L. Rech, and J. Fraga, "HRM smart contracts on the blockchain: emulated vs native," Cluster Computing, vol. 23, no. 3, pp. 2105-2122, 2020.

[165] Y. Chen, X. Wang, Y. Yang, and H. Li, "Location-aware WiFi authentication scheme using smart contract," Sensors, vol. 20, no. 4, p. 1062, 2020.
[166] B. Wang, W. Liu, M. Wang, and W. Shen, "Research on bidding mechanism for power grid with electric vehicles based on smart contract technology," Energies, vol. 13, no. 2, p. 390, 2020.

[167] K. Patel and M. L. Das, "Transcript management using blockchain enabled smart contracts," in Proceedings of the International Conference on Distributed Computing and Internet Technology, pp. 392-407, Bhubaneswar, India, January 2020.

[168] Y. Nakamura, Y. Zhang, M. Sasabe, and S. Kasahara, "Exploiting smart contracts for capability-based access control in the internet of things," Sensors, vol. 20, no. 6, p. 1793,2020

[169] S. Shahab and Z. Allam, "Reducing transaction costs of tradable permit schemes using Blockchain smart contracts," Growth and Change, vol. 51, no. 1, pp. 302-308, 2020.

[170] T. Sultana, A. Almogren, M. Akbar, M. Zuair, I. Ullah, and N. Javaid, "Data sharing system integrating access control mechanism using blockchain-based smart contracts for IoT devices," Applied Sciences, vol. 10, no. 2, p. 488, 2020.

[171] M. Debe, K. Salah, M. H. Ur Rehman, and D. Svetinovic, "Monetization of services provided by public fog nodes using blockchain and smart contracts," IEEE Access, vol. 8, pp. 20118-20128, 2020.

[172] D. Han, C. Zhang, J. Ping, and Z. Yan, "Smart contract architecture for decentralized energy trading and management based on blockchains," Energy, vol. 199, Article ID 117417, 2020.

[173] S. Xuan, L. Zheng, I. Chung et al., "An incentive mechanism for data sharing based on blockchain with smart contracts," Computers \& Electrical Engineering, vol. 83, Article ID 106587, 2020.

[174] Z. Fu, P. Dong, and Y. Ju, "An intelligent electric vehicle charging system for new energy companies based on consortium blockchain," Journal of Cleaner Production, vol. 261, Article ID 121219, 2020.

[175] N. Matai, K. Vibho, and R. A. Uthra, "Blockchain implementation using smart contracts to secure the online real estate business transactions," International Journal of Advanced Science and Technology, vol. 29, no. 6, pp. 2462-2473, 2020.

[176] J. D. Vyas, M. Han, L. Li, S. Pouriyeh, and J. S. He, "Integrating blockchain technology into healthcare," in Proceedings of the ACM Southeast Conference, pp. 197-203, Tampa, FL, USA, April 2020.

[177] F. Jamil, S. Ahmad, N. Iqbal, and D.-H. Kim, "Towards a remote monitoring of patient vital signs based on IoT-based blockchain integrity management platforms in smart hospitals," Sensors, vol. 20, no. 8, p. 2195, 2020.

[178] D. Prashar, N. Jha, S. Jha, Y. Lee, and G. P. Joshi, "Blockchain-based traceability and visibility for agricultural products: a decentralized way of ensuring food safety in India," Sustainability, vol. 12, no. 8, p. 3497, 2020.

[179] V. Reniers, Y. Gao, R. Zhang et al., "Authenticated and auditable data sharing via smart contract," in Proceedings of the 35th Annual ACM Symposium on Applied Computing, pp. 324-331, Brno, Czech Republic, March 2020.

[180] E. Kurnia, T. Djatna, and F. Udin, "Analysis and design of transparent smart contract based on blockchain technology for supply chain in "Gasol flour" industry," in Proceedings of the International Conference on Food and Bio-Industry, Article ID 012027, Bandung, Indonesia, July 2019.

[181] M. A. Habib, M. B. Sardar, S. Jabbar, C. N. Faisal, N. Mahmood, and M. Ahmad, "Blockchain-based supply chain for the automation of transaction process: case study based validation," in Proceedings of the International 
Conference on Engineering and Emerging Technologies (ICEET), pp. 1-7, Lahore, Pakistan, February 2020.

[182] N. Neysen, "Blockchain and smart contracts in the recording industry," European Research Studies Journal, vol. 23, no. 2, pp. 174-185, 2020.

[183] M. Zghaibeh, U. Farooq, N. U. Hasan, and I. Baig, "SHealth: a blockchain-based health system with smart contracts capabilities," IEEE Access, vol. 8, pp. 70030-70043, 2020.

[184] K. Luchoomun, S. Pudaruth, and S. Kishnah, "Implementation of a proof of concept for a blockchain-based smart contract for the automotive industry in Mauritius," International Journal of Advanced Computer Science and Applications, vol. 11, no. 3, pp. 71-81, 2020.

[185] F. Chiacchio, L. Compagno, D. D’Urso, L. Velardita, and P. Sandner, "A decentralized application for the traceability process in the pharma industry," Procedia Manufacturing, vol. 42, pp. 362-369, 2020.

[186] A. Makmur, V. Endramanto, and G. Wang, "The use of smart contract in utility business," International Journal of Advanced Trends in Computer Science and Engineering, vol. 9, no. 3, pp. 2673-2678, 2020.

[187] X. Gong, E. Liu, and R. Wang, "Blockchain-based IoT application using smart contracts: case study of M2M autonomous trading," in Proceedings of the 5th International Conference on Computer and Communication Systems (ICCCS), pp. 781-785, May 2020.

[188] A. P. Pertiwi, D. Puri, Y. A. Pratama, and G. Wang, "A blockchain-based smart contract system for digital video streaming application," International Journal of Advanced Trends in Computer Science and Engineering, vol. 9, no. 3, pp. 2708-2711, 2020.

[189] F. A. Adrian, W. Husain, G. Wang, and Sfenrianto, "Applying smart contract in e-logistics for monitoring and control," International Journal of Recent Trends in Engineering \& Research, vol. 8, no. 2, pp. 247-250, 2020.

[190] G. Gürsoy, C. M. Brannon, and M. Gerstein, "Using Ethereum blockchain to store and query pharmacogenomics data via smart contracts," BMC Med. Genomics, vol. 13, pp. 1-11, 2020.

[191] M. Shurman, A. A. R. Obeidat, and S. A. D. Al-Shurman, "Blockchain and smart contract for IoT," in Proceedings of the 11th International Conference on Information and Communication Systems (ICICS), pp. 361-366, April 2020.

[192] R. Gupta, V. K. Shukla, S. S. Rao, S. Anwar, P. Sharma, and R. Bathla, "Enhancing privacy through "smart contract" using blockchain-based dynamic access control," in Proceedings of the International Conference on Computation, Automation and Knowledge Management (ICCAKM), pp. 338-343, Dubai, UAE, January 2020.

[193] S. Panja, S. Bag, F. Hao, and B. Roy, "A smart contract system for decentralized borda count voting," IEEE Transactions on Engineering Management, vol. 67, no. 4, pp. 1323-1339, 2020.

[194] C. Udokwu, A. Kormiltsyn, K. Thangalimodzi, and A. Norta, "An exploration of blockchain enabled smart-contracts application in the enterprise," Technical Report, 2018.

[195] F. R. Batubara, J. Ubacht, and M. Janssen, "Challenges of blockchain technology adoption for e-government: a systematic literature review," in Proceedings of the 19th Annual International Conference on Digital Government Research, Governance Data Age, p. 76, New York, NY, USA, May 2018. 